\title{
La implementación en el ordenamiento interno de obligaciones emanadas del Derecho Penal Internacional con especial énfasis en los crímenes internacionales: Una mirada a los procesos en Colombia, Perú y Venezuela $\left.\left.{ }^{(*)}\right)^{(*)}\right)^{(+*+)}$
}

\author{
The implementation of International Criminal Law obligations - particularly \\ international crimes within domestic systems: An overview of processes in \\ Colombia, Peru and Venezuela
}

\author{
Juan Carlos Ospina $a^{(+*+*)}$ \\ Universidad de los Andes (Bogotá, Colombia) \\ Michelle Reyes Milk ${ }^{(* * * *)}$ \\ Pontificia Universidad Católica del Perú (Lima, Perú) \\ Andrea Santacruz Salazar ${ }^{(*+* x+* x)}$ \\ Universidad Metropolitana (Caracas, Venezuela)
}

\begin{abstract}
Resumen: América Latina no ha sido ajena a situaciones de conflicto armado $u$ otras situaciones de violencia. Dichas situaciones nos exigen análisis con enfoques teóricos, así como prácticos. Un factor esencial en estos análisis ha sido -y continúa siendo- la necesidad de asegurar la compatibilidad de los ordenamientos jurídicos nacionales con el Derecho Penal Internacional, con el fin último de luchar contra la impunidad y prevenir la comisión de crímenes internacionales. Ello se traduce en la necesidad de llevar a cabo una implementación integral de las obligaciones emanadas de los tratados relevantes sobre la materia ratificados por los países. Este factor puede garantizar que los países de la región tengan las herramientas jurídicas adecuadas para realizar una
\end{abstract}

$\left(^{*}\right) \quad$ Nota del Equipo Editorial: Este artículo fue recibido el 29 de setiembre de 2021 y su publicación fue aprobada el 30 de noviembre de 2021.

${ }^{* *}$ Todas las opiniones vertidas son a título personal de los autores del artículo.

${ }^{* * *}$ Los autores desean agradecer encarecidamente a Carmela García por su valioso apoyo en este artículo, incluyendo en investigación y edición.

${ }^{(* * *)}$ Profesor en la Universidad de los Andes (Colombia). Asesor Jurídico en la Comisión Colombiana de Juristas (Bogotá, Colombia) y docente de la Universidad de los Andes. Abogado, Especialista en Cultura de Paz, Magíster en Derechos Humanos y candidato a Doctor por la Universidad de los Andes. ORCID: https://orcid.org/0000-0002-5587-1220. Correo electrónico: jc.ospinar1@uniandes. edu.co.

$\left(^{* * * * *}\right.$ Profesora Ordinaria del Departamento Académico de Derecho de la Pontificia Universidad Católica del Perú (PUCP), (Lima, Perú). Consultora en Justicia Internacional, actualmente desempeñándose como Consultora para las organizaciones Women's Initiatives for Gender Justice (La Haya, Países Bajos), No Peace Without Justice (Bruselas, Bélgica), y Due Process of Law Foundation (Washington D.C., EEUU). Abogada por la PUCP (mención sobresaliente) y Máster en Derechos Fundamentales por la Universidad Carlos III de Madrid (mención sobresaliente). ORCID: https://orcid.org/0000-0003-2909-5026. Correo electrónico: reyes.michelle@pucp.edu.pe.

$\left(^{* * * * *}\right.$ ) Profesora de la Universidad Metropolitana - UNIMET (Caracas, Venezuela). Jefa del Departamento de Estudios Jurídicos de la UNIMET y profesora en las cátedras de Derecho Penal, Derecho Penal de los Negocios, Derechos Humanos y Análisis Jurídico en esa misma casa de estudios. Es encargada del Departamento de Estudios Internacionales UNIMET, y Directora Ejecutiva del Centro de Derechos Humanos de la UNIMET. Abogada (Summa Cum Laude) por la UNIMET, Máster en Gerencia Tributaria de Empresas (honores) (UNIMET), y Especializada en Ciencias Penales y Criminológicas (Universidad Central de Venezuela). Actualmente cursa el Doctorado en Derecho en la Universidad Católica Andrés Bello. ORCID: https://orcid.org/0000-0003-0059-4788. Correo electrónico: asantacruz@unimet.edu.ve. 
debida calificación jurídica de las situaciones de conflicto armado o de violencia que puedan ser consideradas como crímenes internacionales y delitos relacionados con el uso de la fuerza por parte de autoridades del Estado; para proceder a una aplicación del marco jurídico respectivo según las características que se reúnan en un contexto y tiempo específico; y para poder judicializar las conductas respectivas con tipos penales que atiendan tanto a la naturaleza de los hechos como al contexto en el que los mismos se llevan a cabo. De este modo, el artículo incluye un análisis del estado de la implementación de las obligaciones internacionales de Colombia, Perú y Venezuela en materia de crímenes internacionales, así como, donde es relevante, de los delitos relacionados con el uso de la fuerza por parte de autoridades del Estado. Con ellos, se busca constatar los aciertos y los vacíos normativos, las prácticas legislativas en la forma de implementación, así como los aportes jurisprudenciales que han complementado los marcos jurídicos existentes.

Palabras clave: Derecho Penal Internacional - Derecho Internacional Humanitario - Corte Penal Internacional - Crímenes de Guerra - Crímenes de Lesa Humanidad - Convenios de Ginebra - Estatuto de Roma - Conflicto Armado - Genocidio - Colombia Perú - Venezuela

Abstract: Latin America has not been unaffected by situations of armed conflict or other situations of violence. These situations require analysis from both theoretical and practical approaches. A key component of these analysis has been - and continues to be - the need to guarantee the compatibility of national legal systems with International Criminal Law, with the aim of fighting against impunity and to prevent the commission of international crimes. This translates into the need to carry out a comprehensive implementation of obligations arising from relevant treaties in this area ratified by States. This factor could guarantee that countries in the region have adequate legal tools to make a correct legal assessment of armed conflicts or situations of violence which may amount to international crimes and crimes related to the use of force by State agents; in order to apply the relevant legal framework according to the characteristics of a specific context and time; and to prosecute criminal conducts using the criminal offenses that best respond to the nature of the events and the context in which they took place. In this sense, this paper contains an analysis of the status of the national implementation in Colombia, Peru and Venezuela of international obligations regarding international crimes as well as, where relevant, crimes related to the use of force by State agents. Thus, the authors aim at identifying legislative successes and gaps, regulatory practices for implementation, as well as the contributions of case-law that have complemented current legal frameworks.

Keywords: International Criminal Law - International Humanitarian Law - International Criminal Court - War Crimes - Crimes Against Humanity - Geneva Conventions - Rome Statute - Armed Conflict - Genocide - Colombia - Peru - Venezuela

\section{Introducción}

Colombia, Perú y Venezuela son tres países que han atravesado situaciones de violencia complejas que, en el caso de Colombia y Perú, han constituido conflictos armados no internacionales, y han llevado a la investigación de crímenes de lesa humanidad, en el caso de Venezuela.

En el caso de Colombia, por más de siete décadas se llevó a cabo un conflicto armado no internacional (CANI) entre el gobierno de Colombia, representado por las Fuerzas Armadas y Fuerzas de Seguridad, y el grupo armado de las Fuerzas Armadas Revolucionarias de Colombia (FARC-EP), que terminó con un Acuerdo de Paz. Empero, Colombia ha sido escenario de no uno sino diversos conflictos armados, que reunieron, y en algunos casos reúnen, a otros actores como el Ejército de Liberación Nacional (ELN); las AUC (Autodefensas Unidas de Colombia); el EPL (Ejército Popular de Liberación), las Ilamadas BACRIM- bandas criminales conformadas por paramilitares desmovilizados, pero también por bandas relacionadas al narcotráfico; y Grupos Armados Organizados Residuales (GAOR), tales como estructuras residuales de FARCEP que no se acogieron al proceso de desmovilización tras la firma del Acuerdo de Paz con el gobierno en el 2016 (Comité Internacional de la Cruz Roja [CICR], 2018).

En el caso del Perú, según lo afirmado y evaluado por el Informe Final de la Comisión de la Verdad y Reconciliación [CVR] (2003), se vivió un conflicto armado no internacional que tuvo una duración de 20 años y seis meses, teniendo como fecha de inicio el 17 de mayo de 1980, día en que se celebraba las elecciones presidenciales, cuando el grupo armado Sendero Luminoso quemó las ánforas electorales en el distrito de Chuschi (Cangallo, Ayacucho) dejando marcado desde entonces su deseo de auto marginarse del proceso democrático. Por su parte, la CVR ha señalado como fecha del fin del conflicto el mes de noviembre del 2000, tras el abandono del territorio por parte del expresidente Alberto Fujimori y su subsiguiente renuncia desde el exterior. EI CANI que se desarrolló en Perú se caracterizó por una comisión 
de crímenes internacionales, así como actos de terrorismo. Otras partes se unieron al conflicto y se enfrentaron entre ellas: el Movimiento Revolucionario Tupac Amaru (MRTA), y grupos paramilitares como el Grupo Colina y el Comando Rodrigo Franco. En su Informe Final, la CVR determinó que Sendero Luminoso fue responsable del $46 \%$ de las muertes y desapariciones reportadas durante su investigación; los agentes del Estados fueron responsables del 30\% de las víctimas; y el restante $24 \%$ fue atribuido a otros actores (MRTA, paramilitares, rondas campesinas, entre otros) (2003, p. 46). En la actualidad, remanentes de Sendero Luminoso -autoidentificados como Militarizado Partido Comunista del Perú- sostienen enfrentamientos con agentes de seguridad en la zona del VRAEM (Valle de los Ríos Apurímac, Ene y Mantaro), con grados variantes de intensidad que llevan a una falta de uniformidad en torno a la calificación de las hostilidades, en gran parte debido a la falta de información (Gurmendi, 2017).

Por su parte, desde hace más de una década, Venezuela vive una situación de crisis de gobernabilidad e institucionalidad en el marco de un gobierno dictatorial responsable por la comisión de graves violaciones a los derechos humanos que reúnen los elementos para caracterizarse como crímenes de lesa humanidad (Misión Internacional Independiente de Determinación de los Hechos sobre la República Bolivariana de Venezuela [MII], 2020). En este contexto, los niveles de violencia y enfrentamientos entre opositores al gobierno y fuerzas armadas y de seguridad se encuentran por debajo del umbral de un conflicto armado- por los criterios de organización e intensidad. Estos enfrentamientos se han dado principalmente en el marco de protestas masivas llevadas a cabo contra el gobierno, y han sido significativas en cuanto a su frecuencia, llevándose a cabo miles de ellas desde el año 2014 (MII, 2020, pp. 15-16).

Dada esta situación -la que se ha vivido, la que se vive, y la que se podría vivir- la necesidad de contar con una implementación adecuada de las obligaciones asumidas en virtud del Estatuto de Roma y el Derecho Penal Internacional (DPI), en particular respecto a la tipificación de los crímenes internacionales, cobra una relevancia particular en la región, incluyendo estos tres países. La tarea de implementación, sin embargo, es una tarea pendiente que se remonta a varias décadas, y se da no sólo de cara al Estatuto de Roma que crea la Corte Penal Internacional, sino también de otras disposiciones relevantes del Derecho Internacional, incluyendo la Convención para la Prevención y la Sanción del Delito de Genocidio de 1948, los Convenios de Ginebra de 1949 y sus Protocolos Adicionales de 1977. Tanto Colombia como Perú y Venezuela han ratificado la Convención para la Prevención y la Sanción del Delito de Genocidio(1), los Convenios de Ginebra y sus Protocolos Adicionales I y $\mathrm{II}^{(2)}$, así como el Estatuto de Roma que crea la Corte Penal Internacional(3).

En el siguiente trabajo, abordaremos entonces los distintos procesos de implementación de los crímenes internacionales con distinciones en cada uno de estos países. Este proceso de implementación va a abarcar, en especial, la implementación de las tres categorías originarias de crímenes internacionales contemplados en el Estatuto de Roma -los crímenes de guerra, especialmente en el caso colombiano, los crímenes de lesa humanidad y el crimen de genocidio- y, donde es aplicable, también el crimen de agresión, por lo que incluiremos referencias a la implementación de los crímenes del Estatuto en su integridad en el caso de Perú y Venezuela.

En esta medida, se tomará como referencia la definición de los crímenes internacionales según el Estatuto de Roma. Así, se entiende por genocidio "cualquiera de los actos mencionados a continuación, perpetrados con la intención de destruir total o parcialmente a un grupo nacional, étnico, racial o religioso como tal" (Estatuto de Roma, 1998, artículo 6). El listado de actos comprende la matanza de miembros del grupo; la lesión grave a la integridad física o mental de los miembros del grupo; el sometimiento intencional del grupo a condiciones de existencia que hayan de acarrear su destrucción física, total o parcial; las medidas destinadas a impedir nacimientos

(1) Colombia ratificó la Convención para la Prevención y la Sanción del Delito de Genocidio en 1959; Perú lo hizo en 1960 y Venezuela en 1960. Véase Convención para la Prevención y la Sanción del Genocidio. (1948, 12 de setiembre). Comité Internacional de la Cruz Roja. https://www.icrc.org/es/doc/resources/documents/misc/treaty-1948-conv-genocide-5tdm6h.htm.

(2) Colombia ratificó los cuatro Convenios de Ginebra en 1961, el Protocolo Adicional I (PAI) en 1993, y el Protocolo Adicional II (PAll) en 1995; Perú lo hizo en 1956, 1989 y 1989, respectivamente, y Venezuela en 1956, 1998 y 1998, respectivamente. Véase CICR. (s. f.). Treaties, State Parties, and Commentaries. International Committee of the Red Cross. https://ihl-databases.icrc.org/applic/ ihl/ihl.nsf/vwTreatiesByCountry.xsp.

(3) Colombia ratificó el Estatuto de Roma en 2002; Perú lo hizo en 2001; Venezuela lo hizo en 2000. Véase Estatuto de Roma de la Corte Penal Internacional. (1998, 17 de julio). Naciones Unidas. https://www.un.org/spanish/law/icc/statute/spanish/rome_statute(s).pdf. 
en el seno del grupo; y el traslado por la fuerza de niños del grupo a otro grupo" (Estatuto de Roma, 1998, artículo 6).

Asimismo, conforme al Estatuto de Roma, "se entenderá por "crimen de lesa humanidad" cualquiera de los actos siguientes cuando se cometa como parte de un ataque generalizado o sistemático contra una población civil y con conocimiento de dicho ataque" (1998, artículo 7 inciso 1). Para este crimen, el listado de actos comprende el asesinato; el exterminio; la esclavitud; la deportación o el traslado forzoso de población; la encarcelación u otra privación grave de la libertad física en violación de normas fundamentales de derecho internacional; la tortura; la violación, esclavitud sexual, prostitución forzada, embarazo forzado, esterilización forzada o cualquier otra forma de violencia sexual de gravedad comparable; la persecución; la desaparición forzada de personas; el crimen de apartheid; y otros actos inhumanos de carácter similar que causen intencionalmente grandes sufrimientos o atenten gravemente contra la integridad física o la salud mental o física (Estatuto de Roma, 1998, artículo 7 inciso 1).

En el caso de los crímenes de guerra, el artículo 8 inciso 2 del Estatuto de Roma distingue las siguientes categorías de crímenes de guerra: infracciones graves de los Convenios de Ginebra de 12 de agosto de 1949 (literal a); otras violaciones graves de las leyes y usos aplicables en los conflictos armados internacionales dentro del marco establecido de derecho internacional (literal b); las violaciones graves del artículo 3 común a los cuatro Convenios de Ginebra de 12 de agosto de 1949 en caso de CANI (literal c); y otras violaciones graves de las leyes y los usos aplicables en los CANIs, dentro del marco establecido de derecho internacional (literal e). Cabe destacar que la configuración de estos crímenes requiere que las conductas prohibidas hayan sido cometidas en el contexto de un conflicto armado (sea internacional o no internacional) y que tengan un nexo con dicho conflicto. Ante la ausencia de una definición del término "conflicto armado" en los tratados de Derecho Internacional Humanitario (DIH), la jurisprudencia del Tribunal Penal Internacional para la ex Yugoslavia [TPIY] estableció en el asunto Tadic que "existe un conflicto armado cuando se recurre a la fuerza armada entre Estados o violencia armada prolongada entre autoridades gubernamentales y grupos armados organizados o entre los grupos armados entre si" (1995, párr. 70, traducción propia). En esta medida, el Estatuto de Roma precisa que el listado de crímenes de guerra en CANI "no se aplica a las situaciones de tensiones internas y de disturbios interiores, tales como los motines, los actos esporádicos y aislados de violencia u otros actos análogos" (1998, artículo 8 inciso 2 literales d y f).

Como apreciaremos en el estudio de estos tres países, la implementación del Estatuto de Roma y de otras obligaciones relevantes de Derecho Internacional, en particular las derivadas de los cuatro Convenios de Ginebra (en adelante, CG) y de sus Protocolos Adicionales (PA I y II), ha sido una tarea compleja, que no ha sido llevada a cabo de manera uniforme, por lo que se han ido implementando, en algunos supuestos, algunas medidas paulatinamente, o incorporando selectivamente algunos de los crímenes dentro de los ordenamientos internos. Así, la tarea no sólo ha sido compleja, sino también tardía, producto de la falta de voluntad y priorización de nuestros legisladores y representantes del Ejecutivo, sumados a concepciones erróneas en torno a las categorías de crímenes internacionales y la falta de entendimiento de la materia. Como señalaremos, esto ha requerido, en algunos contextos -y sigue requiriendo- un rol activo de los operadores jurídicos con el objetivo de llenar estos vacíos normativos, así como realizar tareas de interpretación de cara a las obligaciones internacionales.

Finalmente, además de analizar los procesos y el estado actual en cada uno de los tres países, en el presente artículo abordaremos también la pregunta sobre la existencia o no de una obligación expresa de implementar, así como las ventajas de la implementación.

\section{La implementación de los crímenes internacionales dentro de los ordenamientos internos: ¿existe una obligación de implementar?}

La implementación de las obligaciones internacionales dentro de los ordenamientos internos es un aspecto fundamental del Derecho Internacional. Si bien los Estados se encuentran obligados y deben cumplir con las obligaciones internacionales asumidas, a la luz del principio pacta sunt servanda, la tarea de implementación es una tarea compleja que obliga a mirar con detenimiento tanto la relación de los ordenamientos internos con el Derecho Internacional, como la naturaleza particular de las disposiciones a ser implementadas. Así, si bien los tres países objeto de nuestro análisis -Colombia, Perú, y Venezuela- se acogen a una teoría monista del Derecho Internacional, la naturaleza de las obligaciones asumidas cuando se trata de instrumentos como el del Estatuto de Roma, están compuestas, en su mayoría, por normas 
no autoaplicativas, y requieren idealmente una tipificación expresa en nuestros ordenamientos internos, sobre todo a la luz del principio de legalidad.

En cuanto a la Convención para la Prevención y la Sanción del Delito de Genocidio (Convención contra el Genocidio), debemos destacar que esta norma recoge, de un lado, la definición de genocidio (artículo II) que luego sería recogida en los Estatutos de los Tribunales Penales Internacionales Ad Hoc y en el Estatuto de Roma de la Corte Penal Internacional, y las modalidades que generan responsabilidad penal (artículo III); y de otro lado, establece de manera expresa la obligación de implementar estas disposiciones a nivel interno:

\section{Artículo V}

Las Partes contratantes se comprometen a adoptar, con arreglo a sus Constituciones respectivas, las medidas legislativas necesarias para asegurar la aplicación de las disposiciones de la presente Convención, y especialmente a establecer sanciones penales eficaces para castigar a las personas culpables de genocidio o de cualquier otro de los actos enumerados en el artículo III.

En lo que se refiere a los Convenios de Ginebra y sus Protocolos Adicionales, cabe señalar que, en particular, nos centraremos en la implementación de la categoría de infracciones graves. Así, podemos afirmar que de la disposición común respecto a las sanciones de las infracciones graves contenida en los cuatro Convenios de Ginebra (art. 49 CGI; art. 50 CGII; art. 129 CGIII; art. 146 CGIV) existe una obligación expresa de implementación (énfasis agregado):

\section{Artículo 49 del CGI (50 CGII; 129 CGIII; 146 CGIV)}

Las Altas Partes contratantes se comprometen a tomar todas las medidas legislativas para determinar las adecuadas sanciones penales que se han de aplicar a las personas que hayan cometido, o dado orden de cometer, una cualquiera de las infracciones graves contra el presente Convenio definidas en el artículo siguiente.

(...)

Por su parte, el artículo 86 del Protocolo Adicional I establece la necesidad de adoptar medidas para hacer cesar las infracciones graves, lo que incluye también medidas legislativas al respecto.

\section{Artículo 86 - Omisiones}

1. Las Altas Partes Contratantes y las Partes en conflicto deberán reprimir las infracciones graves y adoptar las medidas necesarias para hacer que cesen todas las demás infracciones de los Convenios y del presente Protocolo que resulten del incumplimiento de un deber de actuar.

(...)

A diferencia de la Convención contra el Genocidio y los Convenios de Ginebra, la obligación de implementar no se plantea de modo expreso en el Estatuto de Roma. Precisamente, el Estatuto de Roma no contiene una obligación expresa de adoptar medidas legislativas para la sanción de los crímenes internacionales que tipifica. Así, la única disposición en el Estatuto que establece una obligación expresa de adoptar medidas nacionales es aquella contemplada en el artículo 88, pero con respecto a la cooperación y asistencia judicial de los Estados respecto a la Corte. De este modo, el artículo 88 establece que "los Estados Partes se asegurarán de que en el derecho interno existan procedimientos aplicables a todas las formas de cooperación especificadas en la presente parte" (énfasis agregado).

¿Qué podemos deducir de esta ausencia de una obligación expresa de implementar (adoptar medidas nacionales legislativas)? Consideramos que si bien el Estatuto de Roma no plantea una obligación expresa de tipificar los crímenes internacionales dentro de los ordenamientos internos, la naturaleza y puesta en práctica del sistema instaurado por el Estatuto de Roma nos lleva a afirmar la existencia de una obligación tácita de implementar los crímenes dentro de cada ordenamiento. Ello, en vista del principio de complementariedad, el pilar del sistema instaurado por el Estatuto que reconoce que los Estados tienen la jurisdicción primaria respecto a los crímenes recogidos en el Estatuto.

Dicho principio se encuentra recogido en los artículos 1 y 17 del Estatuto, así como en su Preámbulo, y se traduce en que la Corte Penal Internacional (CPI) solo podrá ejercer su jurisdicción cuando los Estados carecen de competencia o voluntad para llevar a cabo una investigación y judicialización a nivel interno- el estándar de "no puedo o no quiere". Se puede argumentar que una falta de tipicidad podría llevar a una interpretación de falta de capacidad por parte del Estado para poder llevar a cabo procesos nacionales con tipos adecuados, y donde se utilizarían tipos ordinarios que no reflejarían el alcance pleno de la naturaleza del crimen internacional. Así, si el Estado logra llevar a cabo procesos nacionales que se enfoquen en sustancialmente la misma conducta y dirigidos contra los mismos sospechosos que la Corte investigaría -el test de "misma persona / misma conducta" instaurado por la Corte en Muthaura (CPI, 2011, párr. 39). y Gadaffi (CPI, 2013)- entonces se activaría el 
principio de complementariedad, dando lugar a la primacía de la jurisdicción nacional.

A la luz de la complementariedad, la tarea de implementación del Estatuto de Roma cobra una importancia particular para nuestros países, dado que en dos de ellos -Colombia y Venezuela- se han encontrado bajo análisis frente a la Corte Penal Internacional. En el caso de Colombia, la Fiscalía de la CPI condujo un Examen Preliminar que tuvo 17 años de duración (abierto en el año 2004 y cerrado en octubre de 2021) y tuvo un impacto importante en el proceso de negociación de paz llevado a cabo entre el gobierno y las FARC-EP entre 2012 y 2016, así como en la implementación del proceso de justicia transicional. En el caso de Venezuela, existen dos situaciones ante la Corte Penal Internacional, la primera ("Venezuela I") se inició en febrero de 2018 con la apertura de un Examen Preliminar y recientemente pasó a la etapa de Investigación en noviembre de 2021, y la segunda ("Venezuela II") fue remitida por el propio Estado en febrero de 2020 y se encuentra actualmente bajo Examen Preliminar.

Por último, es importante precisar cuáles son los beneficios de una plena implementación de las obligaciones derivadas del Derecho Penal Internacional, incluyendo la Convención contra el Genocidio, los Convenios de Ginebra y sus Protocolos Adicionales y el Estatuto de Roma, en lo que se refiere a crímenes internacionales. Más allá de cumplir con obligaciones -directas o tácitas- de implementar, la plena implementación permitiría, de ser requerido, juzgar a personas responsables de la comisión de crímenes internacionales con tipos penales adecuados que reflejen la naturaleza del tipo, así como la gravedad. Además, la implementación de crímenes internacionales debe ser vista como una tarea no solo sancionadora, sino también una importante tarea con carácter preventivo y disuasorio, que deja el camino abierto para un marco jurídico adecuado en caso se requiera la investigación y judicialización de crímenes internacionales dentro del sistema nacional de justicia.

\section{Estado de la cuestión: Los procesos de implementación en Perú, Colombia y Venezuela}

La Convención contra el Genocidio de 1948 cuenta con 152 Estados Partes, mientras que los Convenios de Ginebra de 1949 constituyen los únicos tratados de ratificación universal, y han sido ratificados por 196 Estados. Por su parte, el Estatuto de Roma cuenta actualmente con 123 Estados Partes, 29 de ellos en las Américas, incluyendo los 12 Estados sudamericanos (Asamblea de Estados
Partes, s. f.). En materia de implementación de crímenes internacionales, éstos han sido implementados por Argentina, Chile, Colombia, Ecuador, Paraguay, Surinam, y Uruguay ${ }^{(4)}$.

\subsection{Perú: Reflexiones sobre un proceso de implementación inacabado}

El Perú ratificó el Estatuto de Roma el 10 de noviembre de 2001 y se encuentra obligado por este tratado desde su entrada en vigor el 1 de julio de 2002. Asimismo, el Perú es un Estado Parte de la Convención contra el Genocidio desde el año 1960, de los cuatro Convenios de Ginebra de 1949 desde el año 1956 y de sus dos Protocolos Adicionales de 1977 desde el año 1989. No obstante, el Estado peruano no cuenta hasta la fecha con una tipificación integral dentro de su ordenamiento interno de los crímenes internacionales previstos en el Estatuto de Roma, incluyendo los crímenes de lesa humanidad y los crímenes de guerra. En otras palabras, la implementación del Estatuto de Roma se encuentra dentro de las tareas pendientes del Estado peruano, a pesar de las múltiples iniciativas y avances que se han presentado en los últimos 20 años.

Conforme al artículo 55 de la Constitución Política del Perú (CPP), "Ios tratados celebrados por el Estado y en vigor forman parte del derecho nacional" (CPP, 1993). No obstante, las disposiciones del Estatuto de Roma, las disposiciones de la Convención contra el Genocidio sobre la sanción de este crimen y las disposiciones de los Convenios de Ginebra de 1949 y su Protocolo Adicional I sobre la investigación y sanción de las graves infracciones a esos tratados constituyen normas de naturaleza no auto ejecutiva (non self executing) por lo que requieren la adopción de legislación interna para su implementación dentro del ordenamiento peruano. Precisamente, las normas auto ejecutivas son aquellas que contienen "mandatos directos y susceptibles de ser ejecutados de inmediato por autoridades estatales" (Salmón, 2007, p. 84), mientras que las normas no auto ejecutivas son "aquellas

(4) Para mayor información, véase Corte Penal Internacional. (s. f.). National Criminal Jurisdictions. ICC Legal Tools Database. https:// www.legal-tools.org/. 
cuyas provisiones no pueden ser directamente aplicables en el sistema nacional porque necesitan ser complementadas con medidas adicionales de distinta naturaleza" (Salmón, 2007, p. 92). Como señala Salmón, en el caso de la implementación de crímenes de guerra, "tratándose de normas de naturaleza básicamente penal, dicho proceso implica su incorporación en el Derecho interno a través de la tipificación” (2007, p. 248).

A mayor detalle, una implementación integral del Estatuto de Roma incluye la regulación de los tipos penales (crímenes) y sus respectivas penas, los principios del DPI y las disposiciones relativas a la cooperación con la Corte Penal Internacional. Como veremos a continuación, la mayoría de estos aspectos se encuentran pendientes de implementación, salvo por la cooperación.

Sin perjuicio de lo establecido en el artículo 55 de la Constitución, es importante remarcar que cuando nos encontramos frente a tratados internacionales que contienen normas de índole penal, éstas no pueden ser auto-aplicativas, pues requieren una norma penal interna que las desarrolle. Esta postura ha sido recogida por la jurisprudencia de la Corte Suprema de Justicia de la República (2009), a través del último párrafo del fundamento jurídico séptimo del Acuerdo Plenario 9-2009/CJ-116, a saber:

Es cierto que las normas internacionales en materia penal, siempre que tengan un carácter incriminatorio, tienen un carácter de no autoaplicativas - non self executing-, pues requieren de una norma interna de desarrollo (...).

Igualmente, la Sala Penal Especial de la Corte Suprema (2009) ha tenido también oportunidad de ocuparse sobre este asunto en el caso "La Cantuta, Barrios Altos y Sótanos SIE", seguido contra el ex presidente Alberto Fujimori. Allí ha señalado que la aplicación de instrumentos internacionales, si bien pueden formar parte del Derecho Internacional consuetudinario, encuentra su limitación en la exigencia constitucional del principio de legalidad. Asimismo, la Corte Suprema peruana ha hecho énfasis en que el legislador nacional no ha cumplido con las exigencias de tipificación material derivadas de la ratificación por el Perú del Estatuto de Roma y, en consecuencia, de la sanción correspondiente.

Este razonamiento puede ser verificado en el Fundamento Jurídico 711 de la mencionada sentencia, emitida en el año 2009, que señala lo siguiente:

$711^{\circ}$. Las disposiciones indicadas en el primer caso, bajo el ámbito esencial del Estatuto de Nuremberg, en tanto forman parte del Derecho Internacional consuetudinario y se configuraron antes de los hechos de Barrios Altos y La Cantuta, son plenamente aplicables para la labor de subsunción. Sin embargo, es de rigor identificar determinados límites, en tanto (i) se reconoce a esas disposiciones, nucleadas alrededor del Estatuto de Nuremberg, el propio carácter de norma internacional consuetudinaria; (ii) se asume las exigencias constitucionales del principio de legalidad penal [ley previa, estricta, escrita y cierta: artículos $2^{\circ} .24 . d$ ) de la Constitución y II del Título Preliminar del Código Penal], en cuya virtud cabe afirmar, desde una perspectiva material, que no existía en el momento de comisión de los hechos: mil novecientos noventa y uno - mi novecientos noventa y dos una ley que hubiera incorporado una figura penal en nuestro ordenamiento punitivo y que comprenda, de un lado, todos los elementos descritos en esa norma internacional consuetudinaria en cuanto crimen internacional -ni siquiera en la actualidad el legislador ordinario ha cumplido con las exigencias de tipificación material derivadas de la ratificación por el Perú del Estatuto de la Corte Penal Internacional-, y de otro lado, la sanción correspondiente (...) (énfasis añadido).

Las consideraciones expuestas por la Corte Suprema peruana permiten realizar dos conclusiones. La primera, se refiere al incumplimiento por parte del Estado peruano de la obligación internacional derivada de la ratificación y vigencia del Estatuto de Roma, referida a incorporar y/o adecuar su legislación interna. Esta obligación viene dada, además, por el principio de complementariedad. En segundo lugar, se concluye que, en el caso peruano, la imputación de crímenes previstos en el Estatuto de Roma -e incluso otros instrumentos internacionales- requieren necesariamente de desarrollo en la legislación interna.

\subsubsection{Los diversos esfuerzos por implementar el Estatuto de Roma en la legislación nacional}

Al abordar el caso peruano, entonces, analizaremos los diversos esfuerzos por implementar el Estatuto de Roma en la legislación nacional, así como la importancia de contar con esta legislación a la luz del pasado reciente y el presente del Perú.

Conviene, en primer lugar, realizar un repaso por los distintos procesos legislativos que se han dado en el Perú a fin de implementar los crímenes y principios previstos en el Estatuto de Roma. Se trata de un camino lleno de avances y retrocesos desde los primeros esfuerzos en el año 2003, en el marco del proceso de revisión del Código Penal ante la Comisión Revisora del Código Penal constituida en el año 2002. A continuación, se presenta un breve resumen de las iniciativas por implementar el Estatuto 
de Roma tanto como parte de un nuevo Código Penal como mediante leyes específicas, como desarrolla COMISEDH (2019, pp. 17-19):

- 2003: Propuesta legislativa "Adecuación de la Legislación Penal al Estatuto de Roma de la Corte Penal Internacional" presentada por la Comisión Especial Revisora del Código Penal el 10 de diciembre de 2003, comisión que había sido creada en el 2002, mediante la Ley 27937. Esta propuesta plantaba integrar un nuevo Libro dentro del Código Penal. Posteriormente, la Comisión Especial Revisora remitió esta propuesta a la Comisión de Justicia y Derechos Humanos del Congreso de la República para su adopción.

- 2005: La Comisión de Justicia y Derechos Humanos del Congreso adoptó el Proyecto de Ley 14659/2005-CR durante el período legislativo 2001-2006. El proyecto no ser llegó a debatir antes del fin de la legislatura.

- 2007: El 11 de octubre de 2007 se presentó el Proyecto de Ley 1707/2007-CR ante la Comisión de Justicia y Derechos Humanos del Congreso. Siguiendo los lineamientos del proyecto anterior, este proyecto planteaba la incorporación de un Libro Tercero al Código Penal. A pesar de recibir una votación favorable inicial en abril de 2009 , miembros de la Comisión de Justicia y Derechos Humanos plantearon una moción de reconsideración, y el proyecto no logró avanzar ${ }^{(5)}$.

- 2012: En octubre de 2012 se presentó el Proyecto de Ley $1615 / 2012-C R$. Se trataba de un proyecto de ley específico para la implementación del Estatuto de Roma, fue trabajado sobre la base de los anteriores proyectos. Es importante destacar que este proyecto contó con un apoyo multipartidario. Posteriormente, el 9 de diciembre de 2014, este proyecto fue acumulado con otros 152 proyecto de ley en el Dictamen de un texto sustitutorio mediante el cual se propone la Ley del Nuevo Código Penal, aprobado por la Comisión de Justicia y Derechos Humanos y remitido al Pleno del Congreso. Lamentablemente, este proyecto fue archivado en 2016 al culminar el período legislativo 20112016.

- 2016: El 18 de octubre de 2016 se presentó el Proyecto de Ley del Nuevo Código Penal, Proyecto de Ley 498/2016CR, que retomaba el Dictamen de 2014, incluyendo la incorporación de los crímenes del Estatuto de Roma. No obstante, este proyecto no logró ser debatido por la Comisión de Justicia y Derechos Humanos antes del cierre del Congreso de la República en el año 2018.
- 2018 - 2021: El Ejecutivo, a través del Ministerio de Justicia y Derechos Humanos, comenzó a trabajar en un anteproyecto de "Ley para prevenir y sancionar los crímenes internacionales y los delitos contra los derechos humanos". Este anteproyecto fue trabajado entre los años 2018 y 2020, realizándose una entrega simbólica del mismo en febrero de $2020^{(6)}$. Sin embargo, no se logró adoptar esta ley antes del final del período presidencial y parlamentario 2016-2021.

Como se puede observar, la implementación del Estatuto de Roma en el Perú ha constituido, y constituye, una tarea compleja que involucra a todos los Poderes del gobierno, incluyendo el Poder Ejecutivo (en particular, el Ministerio de Justicia y Derechos Humanos y la Comisión Nacional de Estudio y Aplicación del Derecho Internacional Humanitario - CONADIH), el Congreso de la República -cuyas bancadas en las últimas dos décadas han mostrado posturas divergentes-, e incluso las Salas del Poder Judicial, en tanto sobre ellas recae la tarea de aplicar los principios y crímenes previstos en el Estatuto de Roma, así como también las disposiciones sobre cooperación. También ha sido un proceso que ha sido enriquecido por la activa participación de la sociedad civil.

Por otro lado, y enfocándonos en los aspectos sustantivos de estas iniciativas, analizaremos brevemente su contenido en relación a los crímenes y principios recogidos en el Estatuto de Roma, enfocándonos particularmente en los aspectos relacionados a los crímenes de guerra. Para ello, nos centraremos en el anteproyecto de "Ley para prevenir y sancionar los crímenes internacionales y los delitos contra los derechos humanos" (en adelante, Anteproyecto) por tratarse de la iniciativa más reciente sobre la materia y en cuya preparación se han recogido varias de las

(5) Véase Comisión de Justicia y Derechos Humanos del Congreso de la República del Perú. (2009, 14 de abril). Acta de la Décimo Octava Sesión Ordinaria 2008. Período Legislativo 2008-2009. https://www2.congreso.gob.pe/Sicr/ApoyComisiones/comision2008. nsf/1ActasComisiones/64E0FDC014AAA313052575BA0055350E/\$FILE/ACTAJUSTICIA14-21-03-2009.pdf.

(6) Para mayor información, véase Plataforma Única del Estado Peruano. (2020, 22 de febrero). Ministro Fernando Castañeda se compromete a impulsar anteproyecto de ley para prevenir y sancionar crímenes internacionales [nota de prensa]. Plataforma Única del Estado Peruano. https://www.gob.pe/institucion/minjus/noticias/84857-ministro-fernando-castaneda-se-compromete-a-impulsaranteproyecto-de-ley-para-prevenir-y-sancionar-crimenes-internacionales. 
disposiciones y comentarios de las iniciativas precedentes.

En primer lugar, debemos destacar que de los crímenes previstos en el artículo 5 del Estatuto de Roma, solo se encuentra regulado el crimen de genocidio en el Código Penal Peruano en la actualidad. Así, el artículo 319 tipifica el genocidio de la siguiente manera:

Artículo $319^{\circ}$ del Código Penal.- Será reprimido con pena privativa de libertad no menor de veinte años el que, con la intención de destruir, total o parcialmente, a un grupo nacional, étnico, social o religioso, realiza cualquiera de los actos siguientes:

1. Matanza de miembros del grupo.

2. Lesión grave a la integridad física o mental a los miembros del grupo.

3. Sometimiento del grupo a condiciones de existencia que hayan de acarrear su destrucción física de manera total o parcial.

4. Medidas destinadas a impedir los nacimientos en el seno del grupo.

5. Transferencia forzada de niños a otro grupo.

Como se puede observar en el primer párrafo de esta disposición, se ha incorporado la categoría de "grupo social", la cual no se encuentra conforme con la definición internacional recogida en la Convención contra el Genocidio y en el Estatuto de Roma. La incorporación de este supuesto habría atendido a un error al momento de transcribir esta disposición. Por ello, en todos los proyectos de leyes antes mencionados se modifica esta causal a fin de eliminar "social" e incluir al grupo "racial" en su lugar. Adicionalmente, el Anteproyecto incluye una disposición que tipifica la incitación al genocidio, conforme a lo previsto en el artículo III c) de la Convención contra el Genocidio, así como el artículo 25, inciso e) del Estatuto de Roma. Ello cubre una falencia actual del ordenamiento jurídico penal peruano. No obstante, proyectos anteriores también incluían una disposición en relación a las conductas de provocación ${ }^{(7)}$ o incitación ${ }^{(8)}$ al genocidio.

En relación a los crímenes de lesa humanidad, el Código Penal peruano actual contiene un Título XIV-A, denominado "Delitos contra la Humanidad". Sin embargo, este título no incorpora los crímenes de lesa humanidad, sino que tipifica los delitos de genocidio, tortura, desaparición forzada, discriminación y manipulación genética. Estos delitos se encuentran tipificados en su modalidad autónoma, es decir, sin incluir los elementos contextuales requeridos para la categoría de crímenes de lesa humanidad conforme al artículo 7 del Estatuto de Roma, que fueron abordados en la introducción. Este es uno de los aspectos que se busca superar en el Anteproyecto, al distinguir los delitos que constituyen graves violaciones de derechos humanos (ejecución arbitraria, tortura, tratos o penas crueles inhumanos o degradantes, y desaparición forzada) de los crímenes internacionales previstos en el Estatuto de Roma.

A mayor detalle, el Anteproyecto contiene una disposición general que recoge los elementos contextuales de los crímenes de lesa humanidad, así como elementos agravantes. Asimismo, se tipifican un total de 18 conductas de conformidad con las conductas recogidas en el artículo 7 del Estatuto de Roma. A saber, se tipifican las siguientes conductas como crímenes de lesa humanidad: Asesinato; Exterminio; Esclavitud; Deportación o traslado forzoso; Encarcelamiento o privación grave de la libertad; Violación Sexual; Esclavitud Sexual; Prostitución Forzada; Embarazo Forzada; Esterilización Forzada; Unión Forzada; Aborto Forzado; Otras formas de violencia sexual; Persecución; Desaparición Forzada; Tortura; Tratos o penas crueles, inhumanos o degradantes; y Apartheid o segregación racial o étnica. No obstante, se observa que los artículos referentes a la tortura y otros tratos o penas crueles inhumanos o degradantes realizan una remisión a los tipos penales contenidos en la sección relativa a los delitos contra los derechos humanos. Ello se apartaría del estándar establecido en el Estatuto de Roma, en tanto que los crímenes de lesa humanidad no requieren un autor calificado (como sí ocurre en el caso de la Convención contra la Tortura y Otros Tratos o Penas Crueles, Inhumanos o Degradantes de 1984), por lo que estas conductas pueden ser cometidas tanto por agentes estatales ( $y$ quienes actúan bajo su aquiescencia) como por miembros de una organización no estatal (o que quienes actúan con aquiescencia de dicha organización).

En cuanto a los crímenes de guerra, el Anteproyecto incorpora una sección dedicada a estos crímenes que recoge, en primer lugar, disposiciones comunes aplicables a los crímenes de guerra. Estas disposiciones precisan los elementos contextuales - es decir, que deben ser cometidos en el contexto

(7) Véase proyectos de Ley de 2005 y 2007, y dictamen de 2014.

(8) Véase Proyecto de Ley de 2003 
de un conflicto armado (internacional o no internacional) y que deben guardar un nexo con el conflicto armado - así como las categorías de personas protegidas en contextos de conflicto armado internacional y en conflictos armados no internacionales. Asimismo, se recoge ampliamente el artículo 8 del Estatuto de Roma, al recoger los delitos contra personas protegidas; delitos contra el patrimonio y otros derechos protegidos; delitos contra operaciones humanitarias y emblemas; delitos de empleos de métodos prohibidos; y delitos de empleo de medios prohibidos.

Adicionalmente, el Anteproyecto realiza una innovación respecto al artículo 8 del Estatuto de Roma, en tanto que elimina la distinción el listado de conductas prohibidas en el marco de un conflicto armado internacional y el listado de conductas prohibidas en el contexto de un conflicto armado no internacional, salvo cuando la naturaleza de la norma así lo requiere. Asimismo, el Anteproyecto recoge también conductas ausentes en el artículo 8 del Estatuto de Roma, atendiendo a la totalidad de obligaciones internacionales en materia de Derecho Internacional Humanitario. Por ejemplo, se incorpora una agravante en el caso del alistamiento o reclutamiento de menores de 18 años, conforme a lo establecido en el Protocolo Facultativo de la Convención sobre los Derechos del Niño relativo a la participación de los niños en conflictos armados, norma que eleva el estándar general que prohíbe el reclutamiento de menores de 15 años.

Cabe destacar que los esfuerzos por regular los crímenes de guerra se han dado también en el ámbito del Código Penal Militar Policial, aprobado mediante Decreto Legislativo 1094 y publicado el 1 de setiembre de 2010. Esta norma recogía en su redacción inicial a los crímenes de guerra contra personas protegidas por el DIH y los crímenes de guerra relativos a medios y métodos prohibidos. Sin embargo, el Tribunal Constitucional del Perú estableció la inconstitucionalidad de la incorporación de los delitos contra personas protegidas dentro de esta normativa, al considerar que el bien jurídico protegido en estos delitos no es exclusivo de la función militar policial, habida cuenta de que se trata de un bien jurídico común y, por lo tanto, requerirá protección a través de la legislación penal ordinaria (Tribunal Constitucional del Perú, 2015, párr. 216 y siguientes) $)^{(9)}$.

De esta manera, el Tribunal señaló lo siguiente al analizar el artículo 88 del Decreto Legislativo 1094, sobre afectación a personas protegidas por el DIH:

Este Tribunal ha establecido supra que aún en el contexto de un CAI o un CANI, derechos como la vida, la integridad física, la libertad sexual, la libertad de tránsito, la propiedad, la tutela jurisdiccional efectiva, entre otros, no son bienes directamente relacionados con las funciones de las FFAA o la PNP, por lo que requieren ser protegidos mediante la legislación penal común. Por esta razón se declaró inconstitucional el delito contra personas protegidas por el DIH, previsto en el artículo 90 del Decreto Legislativo 961.

Este Tribunal mantiene lo dicho sobre el bien jurídico relevante en el delito contra personas protegidas por el DIH. Se entiende que esta disposición penal -al contemplar el delito contra personas protegidas por el DIH- no persigue proteger el orden y a la disciplina propia del accionar de las FFAA y la PNP, propias del delito de función.

La disposición analizada protege más bien, bienes jurídicos comunes, entre otros, la libertad individual y la integridad física -que no se suspenden inclusive durante los estados de excepción-, frente a la conducta del militar o policía (en actividad) que, en el ejercicio de la función (en acto de servicio o con ocasión de él), realice deportaciones, traslados forzosos o tome como rehenes a personas protegidas por el DIH (Tribunal Constitucional del Perú 2015, párrs. 220-221).

Similar razonamiento aplicó el Tribunal Constitucional del Perú al analizar el artículo 89 (lesiones fuera de combate) y el artículo 90 (confinación ilegal), concluyendo la inconstitucionalidad de estas disposiciones $\mathrm{y}$, en consecuencia, eliminándolas del Código Penal Militar Policial (Tribunal Constitucional del Perú, 2015, párrs. 224-233).

En contraste, al analizar los denominados "Delitos de Empleo de Métodos y Medios Prohibidos en la Conducción de Hostilidades", incluidos en los Capítulos IV y V del Título II del Código Penal Militar Policial, el Tribunal Constitucional del Perú tuvo una consideración distinta. En efecto, al analizar el artículo 91 (métodos prohibidos en las hostilidades) señaló lo siguiente:

Sin afectar la calidad de cosa juzgada de la STC 0012-2006-PFTC, respecto a las normas penales previamente controladas; este Tribunal considera que el dispositivo penal ahora cuestionado resulta susceptible de una distinta interpretación normativa que, al no haber sido advertida en la sentencia precitada, no fue sometida a control.

(9) Esta sentencia reitera lo dispuesto por ese mismo Tribunal en la Sentencia del 15 de diciembre de 2006, recaída sobre el Expediente 0012-2006-AI/TC relativo a la inconstitucionalidad del Decreto Legislativo 961 (Código de Justicia Militar Policial). 
Para este Tribunal resulta evidente que las seis disposiciones penales impugnadas no persiguen sancionar la infracción de bienes jurídicos comunes, sino la incorrección en el uso de la fuerza que, estando sujeta a los principios de necesidad y proporcionalidad, limita los métodos y medios utilizados por las FFAA y la PNP cuando operan en cumplimiento de sus funciones (Tribunal Constitucional del Perú, 2015, párrs. 238-239).

Este razonamiento también fue aplicado a los artículos 92 (medios prohibidos en las hostilidades) y 93 (agravante). En esta medida, el Tribunal Constitucional confirmó la constitucionalidad de estas disposiciones del Código Penal Militar Policial (Tribunal Constitucional del Perú, 2015, párrs. 234-260). El mismo análisis se aplicó también a los delitos contra las operaciones humanitarias y emblemas (artículos 95 y 96) (Tribunal Constitucional del Perú, 2015, párrs. 261278). Por lo tanto, estos crímenes de guerra se encuentran actualmente prohibidos en la legislación peruana a través del Código Penal Militar Policial.

En atención a lo expuesto anteriormente, existirían algunas coincidencias entre los crímenes de guerra tipificados en el Código de Justicia Militar Policial (Decreto Legislativo 1094) y en el Anteproyecto. No obstante, es preciso tomar en cuenta que estas normas tendrán un alcance material distinto, ya que el primero será aplicable únicamente a miembros de las Fuerzas Armadas y Fuerzas de Seguridad del Perú, mientras que, de adoptarse el Anteproyecto, los crímenes regulados en este se encontrarían bajo la justicia penal ordinaria y alcanzarían a la totalidad de las personas bajo la jurisdicción penal peruana.

Por otro lado, destacamos que el Anteproyecto contempla el crimen de agresión, cuya definición se encuentra conforme con el artículo 8 bis del Estatuto de Roma, el cual fue incorporado mediante la Enmienda de Kampala relativa al crimen de agresión. Cabe recordar que la ratificación de esta Enmienda constituye otra de las tareas pendientes del Estado peruano y la incorporación de este tipo penal en el Anteproyecto contribuirá al avance del proceso de ratificación de dicha Enmienda.

En segundo lugar, resulta importante realizar algunos apuntes en torno a la incorporación de los principios del Derecho Penal en el Anteproyecto. De un lado, el Anteproyecto incluye una referencia no solo a la aplicación de los principios del Código
Penal General, sino también a la necesidad de interpretar sus disposiciones conforme al Derecho Internacional y la jurisprudencia de los tribunales internacionales cuya competencia ha aceptado el Perú. De otro lado, resulta fundamental la inclusión en el Anteproyecto de los principios de jurisdicción universal; la responsabilidad de jefes y otros superiores, cuya redacción se adecúa al estándar internacional recogido en el artículo 28 del Estatuto de Roma y cubre un vacío en el actual ordenamiento penal peruano; el estándar relativo a la obediencia debida y las órdenes superiores, de conformidad con el artículo 33 del Estatuto de Roma; la improcedencia del cargo oficial(10); la imprescriptibilidad de los crímenes recogidos en el Anteproyecto, en concordancia con las obligaciones establecidas en el artículo 29 del Estatuto de Roma y la jurisprudencia de la Corte Interamericana de Derechos Humanos $^{(11)}$; y la inaplicabilidad de amnistías, indultos y otras medidas, cuya inclusión atiende a los desarrollos en el Derecho Internacional de los Derechos Humanos así como en el Derecho Penal Internacional(12).

Finalmente, si bien se encuentra pendiente la implementación de la mayoría de los aspectos antes mencionados, el Perú sí cuenta con normativa en materia de cooperación con la Corte Penal Internacional. Precisamente, el Código Procesal Penal, aprobado mediante Decreto Legislativo 957 y publicado el 29 de julio de 2004, dedica la Sección VII del Libro Séptimo a la "Cooperación con la Corte Penal Internacional". Cabe destacar que, con la adopción de esta norma, el Perú se convirtió en uno de los primeros Estados latinoamericanos en implementar disposiciones expresas sobre la materia.

(10) No obstante, la redacción de esta disposición no refleja plenamente la excepción al principio de inmunidad para los crímenes de Derecho internacional, estándar recogido en el artículo 27 del Estatuto de Roma. Entre las iniciativas precedentes, la fórmula establecida en el artículo 5 del Proyecto de Ley 1615/2012CR (Ley de delitos contra el Derecho Internacional de los Derechos Humanos y el Derecho Internacional Humanitario) resulta más adecuada al estándar internacional: "Artículo 5. Improcedencia del cargo oficial. Ninguna persona goza de inmunidad para la investigación o judicialización de los delitos previstos en la presente ley. En ningún caso el cargo oficial de una persona eximirá la responsabilidad penal ni constituirá atenuante para la imposición de la pena".

(11) Para mayor detalle, véase Parenti, P. (2010). La Inaplicabilidad de Normas de Prescripción en la jurisprudencia de la Corte Interamericana de Derechos Humanos. En G. Elsner, K. Ambos \& E. Malarino (coords.), Sistema Interamericano de Protección de los Derechos Humanos y Derecho Penal Internacional (pp. 211-228). KONRAD-ADENAUER-STIFTUNG e. V.

(12) Véase, por ejemplo, Corte Penal Internacional. (2019). Caso Saif Al-Islam Gaddafi. Decisión sobre la Admisibilidad. https://www. icc-cpi.int/Pages/record.aspx?docNo=ICC-01/11-01/11-662 


\subsubsection{La importancia de contar con una implementación integral del Estatuto de Roma en el Perú}

Como hemos destacado, la plena implementación de las obligaciones de $\mathrm{DIH}$, incluyendo la tipificación de los crímenes de guerra, es una tarea que debe cumplirse atendiendo a la obligación expresa derivada de la Convención contra el Genocidio y de los Convenios de Ginebra, y la obligación tácita derivada del Estatuto de Roma y de cara al principio de complementariedad.

Asimismo, la tarea de implementación deberá asumirse con responsabilidad de cara a los compromisos del Estado peruano ante diversos foros multilaterales a completar el proceso de implementación, como lo ha precisado el Perú frente al Consejo de Derechos Humanos en el marco del Examen Periódico Universal; frente a la Asamblea de Estados Partes en la CPI; frente a la Consejo Permanente de la Organización de Estados Americanos en el marco de sus reuniones de trabajo bienales sobre la CPI, entre otros foros (Reyes, 2021).

En particular, completar la tarea de implementación del Estatuto de Roma cobra particular relevancia de cara a la práctica regional, que vislumbra una tendencia hacia la plena implementación del Estatuto de Roma dentro de los ordenamientos internos. Aquí, es posible identificar distintas prácticas legislativas al momento de implementar - sea como remisiones directas al Estatuto, como el caso argentino (Ley 26,200 ); adopción de una ley especial, como es el caso chileno o uruguayo (Ley 20357 y Ley 18026 respectivamente); o implementación al interior del Código Penal, como es el caso de Ecuador vía su Código Orgánico Integral Penal del año 2014. El Perú se ha aproximado a la implementación por dos técnicas legislativas diferentes: ley especial, por un lado, e incorporación en el Código Penal, por otro. Ambas opciones son válidas y dependen de la estrategia legislativa y la oportunidad del momento. Consideramos que, de cara a la presente agenda legislativa, se debería apostar por la que brinde mayor celeridad, dado que ya contamos con importantes antecedentes para la elaboración de esta norma.

Además, una plena implementación de los crímenes internacionales brinda seguridad jurídica en torno a la predictibilidad y el principio de legalidad de la norma, además de la garantía de que el Estado peruano pueda ejercer su jurisdicción de modo primario frente a la CPI. Contar con tipos penales específicos sobre crímenes internacionales se traduce en la existencia de tipos penales que puedan reflejar cabalmente la naturaleza de la norma, así como la gravedad de la misma.

Por otro lado, como hemos mencionado, no debemos olvidar el fuerte valor preventivo y disuasorio de implementar crímenes internacionales. Ello debe traer consigo la capacitación adecuada a los operadores jurídicos, para comprender cabalmente los elementos que cada uno de estos tipos brinda, y la interpretación que la jurisprudencia internacional y comparada ha brindado a estos elementos. Por ejemplo, la Corte Penal Internacional y otros tribunales penales internacionales han brindado importantes lineamientos dentro de su jurisprudencia de cómo entender los elementos contextuales de los crímenes de lesa humanidad y de los crímenes de guerra, tal como se hizo en el caso Katanga (2014) o el caso Al Mahdi (2016) frente a la CPI.

A modo de conclusión, el proceso de implementación de crímenes internacionales representa una oportunidad no solamente para incorporar los tipos penales dentro de nuestro ordenamiento, sino también para incluir otro aspecto fundamental derivado de los tratados relevantes de DIH y DPI: los principios. Así, una plena comprensión y análisis del principio de responsabilidad del superior, por ejemplo, recogido en el artículo 28 del Estatuto de Roma y en las normas consuetudinarias de DIH (Regla 153) permitirian finalmente terminar de incorporar estos principios dentro de nuestro ordenamiento interno.

\subsection{Colombia: Innovaciones jurisprudenciales y el rol de la JEP}

\subsubsection{El marco jurídico de los crímenes de guerra en Colombia}

En este aparte se plantearán las condiciones de la incorporación de los crímenes de guerra en el sistema jurídico colombiano. Para tal efecto, se presentarán las condiciones de incorporación del Estatuto de Roma en el país, incluyendo la reserva realizada por el Estado colombiano frente a los crímenes de guerra; luego se abordarán las luces y sombras del reconocimiento interno de los crímenes de guerra en el Código Penal colombiano; y finalmente, se presentará la situación de conocimiento de dichos crímenes a partir de la reforma constitucional de 2017 y el marco jurídico de funcionamiento de la Jurisdicción Especial para la Paz (JEP).

El Estatuto de Roma (ER) fue adoptado el 17 de julio de 1998 con el voto positivo del Estado colombiano, quien lo suscribió el 10 de diciembre de 1998, y entró en vigor al ser ratificado por sesenta Estados el 1 de julio de 
2001. Luego fue aprobado internamente por medio de la Ley 742 del 5 de junio de 2002, previa autorización constitucional a través del acto legislativo 1 de 2001 que adicionó el artículo 93 de la Constitución Política para establecer que el Estado podía reconocer la jurisdicción de la CPI en los términos del ER y luego ratificar el tratado a través de una ley, siempre que los tratamientos diferentes en materias sustanciales por parte del ER con respecto a las garantías contenidas en la Constitución tendrían efectos exclusivamente dentro del ámbito de la materia regulada en dicho Estatuto. De esta forma, una vez la Corte Constitucional de Colombia (2002) efectuó la revisión de constitucionalidad de dicha ley por medio de la sentencia C-578/02, el ER quedó vigente en el ordenamiento jurídico nacional a partir del 1 de noviembre de ese mismo año.

No obstante, el 5 de agosto de 2002 Colombia excluyó la competencia de la CPI para los crímenes de guerra durante los 7 años siguientes a partir de la entrada en vigencia del ER en el país (1 de noviembre de 2002). La exclusión se basó en el artículo 124 del ER que establece que:

Un Estado, al hacerse parte en el presente Estatuto, podrá declarar que, durante un período de siete años contados a partir de la fecha en que el Estatuto entre en vigor a su respecto, no aceptará la competencia de la Corte sobre la categoría de crímenes a que se hace referencia en el artículo 8 cuando se denuncie la comisión de uno de esos crímenes por sus nacionales o en su territorio.

De acuerdo con esto, la competencia de la CPI sobre los crímenes de guerra cometidos en Colombia solo se activó el 1 de noviembre de 2009. No obstante, es claro que más allá del reconocimiento de la competencia de la CPI para el conocimiento de crímenes de guerra, se tiene que en el marco del conflicto armado existente desde mediados del siglo pasado se han cometido diversos tipos de infracciones del DIH por parte de los actores armados.

Desde junio del año 2004 la Fiscalía de la CPI abrió un examen preliminar sobre Colombia, siendo a la fecha el más largo y activo que ha tenido. Como lo ha reiterado en sus informes dicha Fiscalía, "la Corte sólo puede ejercer su competencia sobre crímenes de guerra cometidos desde el $1^{\circ}$ de noviembre de 2009, de conformidad con la declaración formulada por Colombia con arreglo al artículo 124 del Estatuto" (Fiscalía de la CPI, 2020, párr. 107). Esto quiere decir que la impunidad de los crímenes de guerra cometidos en el marco del conflicto armado en dicho marco temporal está asegurada para efectos de la actuación de la justicia penal internacional. No obstante, una lectura interna de los crímenes de guerra y la creación de la JEP plantea un panorama novedoso desde el derecho comparado que es relevante mencionar.

El Código Penal del año 2000, aprobado mediante la ley 599 y que continúa vigente, incorporó un título de delitos contra personas y bienes protegidos por el DIH (artículos 135 a 164). Dicho título se ha modificado y ampliado en los últimos veinte años hasta integrar un cuerpo normativo que resulta útil para el juzgamiento de infracciones contra el DIH.

Los delitos existentes en la legislación nacional contra personas protegidas ${ }^{(13)}$ por el DIH con ocasión y en desarrollo del conflicto armado (CA) son: Homicidio, con una sanción de prisión de 40 a 50 años $^{(14)}$ : lesiones (daño a la integridad física o a la salud); tortura (dolores o sufrimientos graves, físicos o síquicos); acceso carnal violento; acceso carnal abusivo en persona protegida menor de catorce años; actos sexuales violentos; actos sexuales con persona protegida menor de catorce años; esterilización forzada (privación de la capacidad de reproducción biológica); embarazo forzado; desnudez forzada; aborto forzado; prostitución forzada; esclavitud sexual; trata de personas en persona protegida con fines de explotación sexual; utilización de medios y métodos de guerra ilícitos; perfidia; actos de terrorismo (con ocasión y en desarrollo del conflicto armado); actos de barbarie; tratos inhumanos y degradantes y experimentos biológicos en persona protegida; actos de discriminación racial; toma de rehenes; detención ilegal y privación del debido proceso; constreñimiento a apoyo bélico; despojo en el campo de batalla; omisión de medidas de socorro y asistencia humanitaria; obstaculización de tareas sanitarias y humanitarias; destrucción

(13) El listado de personas protegidas en la legislación nacional incluye a: 1. Los integrantes de la población civil; 2. Las personas que no participan en hostilidades y los civiles en poder de la parte adversa; 3 . Los heridos, enfermos o náufragos puestos fuera de combate; 4. El personal sanitario o religioso; 5 . Los periodistas en misión o corresponsales de guerra acreditados; 6 . Los combatientes que hayan depuesto las armas por captura, rendición u otra causa análoga; 7. Quienes antes del comienzo de las hostilidades fueren considerados como apátridas o refugiados; 8 . Cualquier otra persona que tenga aquella condición en virtud de los Convenios I, II, III y IV de Ginebra de 1949 y los Protocolos Adicionales I y II de 1977 y otros que llegaren a ratificarse.

(14) La pena prevista en este artículo se aumentará de la tercera parte a la mitad cuando se cometiere contra una mujer por el hecho de ser mujer. 
y apropiación de bienes protegidos ${ }^{(15)}$; destrucción de bienes e instalaciones de carácter sanitario; destrucción o utilización ilícita de bienes culturales y de lugares de culto; ataque contra obras e instalaciones que contienen fuerzas peligrosas; represalias; deportación, expulsión, traslado o desplazamiento forzado de población civil; atentados a la subsistencia y devastación; omisión de medidas de protección a la población civil; reclutamiento ilícito; y exacción o contribuciones arbitrarias; y destrucción del medio ambiente.

Dichas conductas son compatibles con el listado de manifestaciones del crimen de guerra establecido en el artículo 8 del ER, sin que sea exhaustivo. En esa medida, existe un amplio catálogo de manifestaciones de los crímenes de guerra, que cumplen con el criterio contextual de dichos crímenes, aunque a la luz del ER sea necesario considerar, por ejemplo, el elemento subjetivo (que el autor haya sido consciente de las circunstancias de hecho que establecían la protección del DIH) y la conciencia de las circunstancias de hecho que establecían la existencia de un conflicto armado. Igualmente, resulta relevante mencionar que el Código Penal colombiano incorpora una cláusula imprescriptibilidad de la acción penal para los crímenes de guerra (artículo 83).

De acuerdo con esto, la legislación colombiana establece un número importante de conductas sancionadas por infracciones del DIH que generan condiciones adecuadas para la lucha contra la impunidad. No obstante, el juzgamiento completo de las posibles infracciones al DIH, especialmente en referencia al ER, no se alcanza con dicho marco ordinario. Por ello es relevante mencionar el contexto de incorporación constitucional de amplias fuentes de derecho internacional para luchar contra la impunidad en el proceso de justicia transicional derivado del Acuerdo de Paz de 2016.

\subsubsection{Los crímenes de guerra y la Jurisdicción Especial para la Paz}

La creación de la JEP, con ocasión del Acuerdo de Paz suscrito entre el Estado colombiano y las FARC-EP, abrió un nuevo paradigma para la lectura de los crímenes internacionales, incluyendo los crímenes de guerra, en la lucha contra la impunidad. La JEP es el componente judicial del Sistema Integral de Verdad, Justicia, Reparación y No Repetición creado para la satisfacción de los derechos de las víctimas del conflicto armado interno a través de la administración de justicia respecto de las graves violaciones a los derechos humanos y las infracciones al DIH ocurridas en este.

Al menos tres razones soportan el nuevo paradigma mencionado: i) la incorporación constitucional del DIH y del derecho penal internacional como fuente de derecho aplicable directamente por la JEP para la calificación jurídica de las conductas; ii) la determinación de las conductas no amnistiables de conformidad con lo establecido en el Estatuto de Roma; y iii) el alcance temporal de las competencias de la CPI y la JEP frente a las conductas que constituyen crímenes de guerra.

La primera razón surge del artículo transitorio 5 del título transitorio de la Constitución, incorporado mediante el acto legislativo 1 de 2017, que establece que la JEP realizará una calificación jurídica propia de las conductas a partir del "Código Penal Colombiano y/o en las normas de Derecho Internacional en materia de Derechos Humanos (DIDH), Derecho Internacional Humanitario (DIH) o Derecho Penal Internacional (DPI)" (énfasis añadido). De acuerdo con dicha disposición, como lo señaló la Corte Constitucional en la sentencia C-080 de 2018, "corresponde dar aplicación directa al Derecho Penal Internacional en la JEP para efectos de la calificación jurídica de la conducta" (énfasis añadido), lo que incluye, entre otros, los tratados internacionales de DPI suscritos por Colombia como el Estatuto de Roma (Ley 742 de 2002) y los elementos de los crímenes (Ley 1268 de 2008).

La segunda razón se encuentra vinculada a la determinación de los crímenes de competencia de la JEP, es decir, aquellos que no pueden ser objeto de amnistía (aplicable a exintegrantes de las FARC-EP) ni de renuncia a la persecución penal (aplicable a integrantes de la Fuerza Pública y a terceros). Así, los artículos 23 de la ley 1820 de 2016 y 42 y 45 de la ley 1957 de 2019 establecen que no serán amnistiables ni renunciables "Ios delitos de lesa humanidad, el genocidio, los crímenes de guerra, la toma de rehenes u otra privación grave de la libertad, la tortura, las ejecuciones extrajudiciales, la desaparición forzada, el acceso carnal violento y otras formas de violencia sexual, la sustracción de menores, el desplazamiento forzado,

(15) Estos son: Los de carácter civil que no sean objetivos militares; 2. Los culturales y los lugares destinados al culto. 3. Los indispensables para la supervivencia de la población civil; 4. Los elementos que integran el medio ambiente natural; y 5. Las obras e instalaciones que contienen fuerzas peligrosas. 
además del reclutamiento de menores, todo ello conforme a lo establecido en el Estatuto de Roma" (énfasis añadido).

De acuerdo con estas dos razones, a diferencia de lo que ocurría antes de la reforma constitucional de 2017, en donde la aplicación del Estatuto de Roma no era directa para la calificación jurídica de las conductas, sino que se contaba con las conductas prohibidas que constituyen infracciones al DIH incorporadas en el Código Penal, la JEP puede utilizar la definición de crímenes de guerra que allí se incorpora. Pero ¿desde cuándo es aplicable el ER para la calificación de los crímenes de guerra? De esta pregunta se deriva la tercera razón y la conclusión del planteamiento. El ER se encuentra vigente como fuente directa para la determinación de crímenes de guerra desde el 1 de noviembre de 2002, así la competencia de la CPI frente a dichos crímenes se hubiera activado solo 7 años después.

Por esa razón, la JEP puede realizar la subsunción de conductas que constituyen crímenes de guerra, en sus diversas manifestaciones, cometidos a partir del 1 de noviembre de 2002 de manera directa a partir del ER incorporado mediante la Ley 742 de 2002. Incluso, bajo una lectura más amplia, es posible afirmar que el ER es fuente del DPI desde su aprobación el 17 de julio de 1998, y que las normas del DIH con anterioridad establecían una prohibición clara a la comisión de dichos crímenes $^{(16)}$. Esto resulta relevante siempre y cuando la JEP continúe con una interpretación sistemática de las fuentes que le permiten luchar contra la impunidad, considerando en contraste las fuentes de derecho aplicables a la calificación jurídica propia que establecen los artículos transitorios 5 y 22 del acto legislativo 1 de 2017, y que deben ser tomadas para la calificación de las conductas cometidas por todas las personas sometidas a su competencia, sin distinción.

De acuerdo con la Corte Constitucional colombiana en la sentencia C-080 de 2018, mediante la cual se analizó la constitucionalidad de la ley estatutaria de la JEP:

La calificación jurídica de la conducta por la JEP debe basarse, en consecuencia, en una norma previa a la comisión de la misma. La valoración de la existencia de dicha prohibición o no, la realizará la JEP en ejercicio de su competencia, quien, para la calificación jurídica, deberá asegurar que la conducta estaba claramente prohibida antes de la comisión del hecho en la Constitución, en el Código Penal vigente, en normas internacionales de Derechos Humanos, o en normas internacionales de Derecho Internacional Humanitario, o en normas imperativas de ius cogens. Así, por ejemplo, constituye norma de ius cogens la Cláusula Martens $y$, en general, las normas de Derecho Internacional Humanitario aplicables a los conflictos armados que instituyen "principios elementales de humanidad", también referidos en el artículo 3 común a los Convenios de Ginebra (tratándose de conflictos armados de carácter no internacional).

Esta amplitud del principio de legalidad "obedece al conocimiento internacional acumulado, a la necesidad de una defensa progresiva de la dignidad en los conflictos armados, a la pluralidad de fuentes del derecho internacional, y a la importancia de proteger los derechos de las víctimas".

De esta manera, esta comprensión del principio de legalidad para efectos de la calificación de la conducta asegura el principio de legalidad como garantía del debido proceso y, así mismo, el derecho de las víctimas a la justicia frente a las graves violaciones a los derechos humanos e infracciones al Derecho Internacional Humanitario.

De acuerdo con lo expuesto, el ordenamiento jurídico colombiano cuenta con un andamiaje que le permite el juzgamiento, acorde con el Código Penal, de infracciones contra el derecho internacional humanitario que es relevante dado el contexto de conflicto armado interno. Adicionalmente, con ocasión de la creación de la JEP, la Constitución Política autorizó a dicha jurisdicción realizar calificaciones jurídicas propias con el propósito de luchar contra la impunidad, es decir, tomar como fuente directa, además de la legislación nacional, el DIH y el Derecho Penal Internacional con el propósito de delimitar las conductas sin sujeción exclusiva al Código Penal. Esta facultad amplía la incorporación interna de los instrumentos internacionales referidos a las infracciones al DIH y que contienen otras manifestaciones de los crímenes de guerra no incorporadas en la legislación nacional ${ }^{(17)}$, por lo que se trata de la comprensión más sofisticada de lucha contra la impunidad frente a dichos crímenes.

\subsection{Venezuela: Algunas consideraciones sobre la implementación del Estatuto de Roma}

Venezuela firmó el Estatuto de Roma de la Corte Penal Internacional el 14 de octubre de 1998, y lo ratificó el 07 de junio de 2000

(16) Por ejemplo, el Protocolo II adicional a los Convenios de Ginebra de 1949 relativo a la protección de las víctimas de los conflictos armados sin carácter internacional, 1977.

(17) Esta facultad aplica también para los crímenes de lesa humanidad (CLH). Esto es especialmente relevante en la medida que en la legislación nacional no se encuentran incorporadas manifestaciones de los CLH, incluyendo sus elementos contextuales. Así las cosas, frente a los CLH la ampliación de las fuentes para la calificación jurídica propia de la JEP es determinante. 
(Asamblea de Estados Parte, s. f.). El 13 de diciembre de ese mismo año, fue publicada la Ley Aprobatoria del Estatuto de Roma de la Corte Penal Internacional en la Gaceta Oficial extraordinaria No. 5.507, y entró en vigor el 01 de julio de 2002. Esto coloca al Estado venezolano entre los primeros de la región en firmar y ratificar el Estatuto, y es uno de los 123 Estados Parte del Sistema del Estatuto de Roma.

La Constitución de la República Bolivariana de Venezuela de 1999 (CRBV), en su artículo 154, establece que los tratados celebrados por la República deben ser aprobados por la Asamblea Nacional antes de su ratificación. Dicho artículo establece como excepciones:

(...) aquellos mediante los cuales se trate de ejecutar o perfeccionar obligaciones preexistentes de la República, aplicar principios expresamente reconocidos por ella, ejecutar actos ordinarios en las relaciones internacionales o ejercer facultades que la ley atribuya expresamente al Ejecutivo Nacional (CRBV, 24 de marzo de 2000).

De las fechas antes señaladas, se evidencia que Venezuela ratificó el Estatuto de Roma antes de la publicación de la ley aprobatoria, lo que nos permite presumir que se consideró que el mismo permitía perfeccionar obligaciones preexistentes de la República, específicamente obligaciones internacionales asumidas tras el fin de la Segunda Guerra Mundial, especialmente las de investigar, juzgar y condenar a los responsables de la comisión de crímenes atroces, para así acabar con la impunidad, y contribuir a la prevención de otros crímenes (Ley Aprobatoria del estatuto de Roma de la Corte Penal Internacional, 13 de diciembre de 2000).

Debemos destacar que Venezuela ha tenido voluntad para prevenir los peores crímenes que ha conocido la humanidad, especialmente los crímenes de guerra, desde principios del siglo $\mathrm{XX}$, asumiendo diversas obligaciones internacionales: en 1907 ratificó la Convención II de La Haya (sobre la ley y costumbre de la guerra terrestre) y firmó las Convenciones IV y IX de La Haya (la primera sobre la guerra en tierra y sus regulaciones, y la segunda sobre bombardeos sobre las fuerzas navales). En 1956, ratificó las convenciones de Ginebra, y en 1998 los protocolos especiales I y ||(18).

Además, Venezuela se adhirió al Acuerdo para el establecimiento de un Tribunal Militar Internacional encargado del juicio y castigo de los principales criminales de guerra del Eje Europeo, firmado en Londres el 8 de agosto de 1945, a partir del cual se constituyó el Tribunal Internacionales Militares de Núremberg. Esto evidencia una voluntad de poner fin a la impunidad frente a los crímenes atroces.

Por otra parte, se adhirió a la Convención para la Prevención y la Sanción del Delito de Genocidio, el 12 de julio de 1960, presentando dos notificaciones y una reserva, lo que demuestra que el Estado atendía los llamados de la comunidad internacional para hacer frente a los horrores que se conocieron después de 1945, lo cual alcanzó su momento cumbre con el Estatuto de Roma, con el que Venezuela se somete a la jurisdicción de la $\mathrm{CPI}$ de manera complementaria, sí y solo sí el Estado no quiere o no puede ejercer la jurisdicción penal sobre los más altos responsables de cometer genocidio, agresión, crímenes de lesa humanidad o crímenes de guerra.

Lamentablemente, aún hoy en día y después de haber entrado en vigor el Estatuto, no se han podido prevenir totalmente los crímenes atroces, esto se puede observar en diversos países, e incluso Venezuela tiene abiertos dos Exámenes Preliminares en este momento.

El 8 de febrero de 2018, la entonces Fiscal Fatou Bensouda anunció el inicio de un examen preliminar sobre la situación de Venezuela, considerando los hechos ocurridos en el país desde abril de 2017. El 27 de septiembre de ese año, Colombia, Chile, Canadá, Perú, Paraguay y Argentina remitieron la situación de Venezuela, en su condición de Estados Parte, y solicitaron que el análisis de la información se realizara desde los hechos acaecidos el 12 de febrero de 2014. Este examen preliminar se conoce hoy como Venezuela I, porque el 13 de febrero de 2020 el Estado venezolano remitió una situación distinta, Venezuela II, en la que alega que:

Se han cometido crímenes de lesa humanidad en el territorio de Venezuela "como resultado de la aplicación de medidas coercitivas ilegales adoptadas unilateralmente por el gobierno de los Estados Unidos de América (los "Estados Unidos") contra Venezuela, al menos desde el año 2014" (Fiscalía de la Corte Penal Internacional, 2020, párr. 91).

Dichos exámenes preliminares se encuentran en etapas distintas ante la Fiscalía de la CPI. Venezuela I estuvo en fase tres, es decir se está analizando su admisibilidad

(18) Véase información de la firma y ratificación de otros pactos internacionales de Derecho Internacional Humanitario en https://ihldatabases.icrc.org/applic/ihl/ihl.nsf/vwTreatiesByCountrySelected.xsp?xp_countrySelected=VE 
(Fiscalía de la Corte Penal Internacional, 2020, párrs. 207-209) hasta la visita del Fiscal Khan al país, cuando anunció que dicho examen terminaba y se daba inicio a la etapa de investigación, el 3 de noviembre de 2021; mientras que Venezuela II se mantiene como examen preliminar, en fase dos, por lo que se está analizando la competencia de la Corte (Fiscalía de la Corte Penal Internacional, 2020, párr. 104).

Venezuela I ha implicado un análisis del principio de complementariedad, lo que ha generado importantes inquietudes sobre la capacidad del Estado venezolano para juzgar y condenar a los posibles responsables de crímenes atroces que han podido ocurrir en el país, y sobre los que la fiscalía de la CPI tiene motivos razonables para considerar su comisión (Fiscalía de la Corte Penal Internacional, 2020, párr. 202).

El principio de complementariedad es fundamental en el análisis que se haga de la implementación del Estatuto de Roma en cada uno de los Estados parte, por lo tanto, en este artículo se pretende hacer un esbozo de la situación actual de implementación general del Estatuto de Roma en Venezuela, para lo cual se analizará de manera general el principio de complementariedad, y se indicarán algunas limitaciones o problemas relacionados a la implementación.

\subsubsection{El principio de complementariedad en Venezuela} Como hemos preciado, el Estatuto de Roma establece en su preámbulo, así como en sus artículos 1 y 17, el principio de complementariedad, que en palabras llanas significa que las primeras instituciones llamadas a hacer justicia son las jurisdicciones penales nacionales, y solo cuando los Estados no quieren o no pueden juzgar, será la CPI la llamada a hacerlo.

En la Resolución ICC-ASP/8/Res.9, se establece como aspectos fundamentales para analizar dicho principio, la falta de capacidad y la falta de voluntad ${ }^{(19)}$ del Estado Parte (Asamblea de Estados Parte, 25 de marzo de 2010).
Al hablar de la falta de capacidad se hace referencia a un punto que ha sido debatido en Venezuela, "la ausencia o ineficacia de un marco legislativo de aplicación", pues en el país aunque existe una ley aprobatoria, no se cuenta con una ley de incorporación como la que se consideró debían tener los países europeos, ni se adoptó la legislación interna, ni se ha tipificado en el Código Penal ninguno de los crímenes atroces, ni tampoco se ha hecho una enmienda o reforma constitucional, como la que realizó Alemania en su momento (Moya, 2019, pp. 497-500).

Thairi Moya considera que no se ha logrado la implementación del Estatuto en Venezuela, "ni siquiera se ha logrado una mínima compaginación entre ese tratado y el derecho local" (Moya, 2019, p. 500). Por ello, incluso algunos abogados, como Fernando Fernández, han trabajado en la creación de un proyecto de Código de Derecho Penal Internacional(20).

Ahora bien, crear un Código de Derecho Penal Internacional o una ley de incorporación, o seguir un proceso de incorporación del Estatuto a la normativa interna es algo que sin duda puede realizarse, pero ello no significa que en este momento no podrían juzgarse los crímenes atroces en la jurisdicción penal venezolana. La base de esa posibilidad positiva está en entender al Estatuto de Roma como una norma de derechos humanos, y por lo tanto forma parte del bloque de constitucionalidad, de acuerdo con lo establecido en el artículo 23 de la Constitución venezolana ${ }^{(21)}$, el cual

(19) “(...) Hay múltiples motivos para la falta de actividad a la hora de llevar a cabo procesamientos nacionales genuinos, que pueden estar relacionados con la falta de capacidad para hacerlo. En este sentido, son de particular interés los asuntos técnicos o de capacidad correspondientes a la ausencia o ineficacia de un marco legislativo de aplicación, las limitaciones en cuanto a conocimientos expertos y experiencia en materia de investigaciones, el fracaso a la hora de asignar prioridad a las causas graves, la falta de recursos del sistema judicial, la ausencia de un programa nacional efectivo de protección de testigos o de seguridad de los magistrados y los fiscales y de ejecución de las penas, o una ausencia general de capacidad y de medios.

10. Estos retos pueden afectar de forma particular a varios Estados que cuentan con la voluntad y la intención de poner fin a la impunidad pero que carecen de los correspondientes recursos, conocimientos expertos y capacidad, así como de un estamento judicial competente e independiente.

11. La falta de voluntad constituye un reto especial a la hora de llevar a cabo procesamientos nacionales genuinos. Esta situación podría darse de resultas de la injerencia política en la judicatura y la complicidad gubernamental en la comisión de los crímenes, y se puede manifestar como una falta de voluntad a la hora de lograr la detención de los sospechosos. Si bien este documento no estudia en detalle la falta de voluntad, importa tener presente que la asistencia y la cooperación por sí solas no resolverán todas las cuestiones de impunidad (...)".

(20) Véase http://www.estudiosconstitucionales.com/REDIAJ/953-1006.pdf.

(21) "Artículo 23. Los tratados, pactos y convenciones relativos a derechos humanos, suscritos y ratificados por Venezuela, tienen jerarquía constitucional y prevalecen en el orden interno, en la medida en que contengan normas sobre su goce y ejercicio más favorables a las establecidas por esta Constitución y en las leyes de la República, y son de aplicación inmediata y directa por los tribunales y demás órganos del Poder Público". 
establece que los pactos y tratados internacionales en materia de derechos humanos, suscritos y ratificados por la República tienen jerarquía constitucional, y son de aplicación inmediata y directa por los tribunales.

Esto último es un punto en discusión, que no ha sido resuelto por instancia judicial alguna, a diferencia de Colombia, en donde su Corte Constitucional, en la sentencia C-370 de 2006, indicó claramente que: "El Estatuto de Roma, mediante el cual se crea la Corte Penal Internacional, constituye probablemente el mayor instrumento internacional de protección a los derechos humanos y al Derecho Internacional Humanitario (...)" (Corte Constitucional Colombiana, 2006); lo cual fue ratificado al señalar en la sentencia C-488/09, que la tipificación de los crímenes atroces, especialmente el genocidio, es una forma de protección de los derechos humanos (Corte Constitucional Colombiana, 2009).

Andrea Santacruz, en un artículo próximo a ser publicado, señala:

Los tratados en materia de derechos humanos se caracterizan porque su objeto y fin es la protección de derechos humanos, ello no significa que solo serán aquellos que reconozcan y protejan derechos humanos, pues la visión de protección a los individuos debe ser lo más amplia posible, entendiendo el protagonismo de las personas en el derecho. En consecuencia, deben incluirse como tratados de derechos humanos aquellos cuyo objeto principal no se relacione con el área, pero que contenga disposiciones de derechos humanos, disposiciones de protección a los derechos humanos (...) (Santacruz, s. f.).

Sobre esto también ha expuesto Carlos Ayala Corao, quien ha señalado:

(...) los tratados que tienen por objeto y propósito la protección de los derechos que emanan de la dignidad de la persona humana, son tratados relativos a los derechos humanos. Tal es el caso de los tratados sobre derechos humanos tanto del sistema universal (ONU) como del sistema interamericano (OEA). Sin embargo, en otros casos, aunque los tratados no tienen el objeto propio de reconocer derechos humanos, sí tienen por propósito la protección de las víctimas de violación de los derechos humanos o asegurar la investigación y sanción de los responsables de los crímenes internacionales contra los derechos humanos. Tal es el caso del Estatuto de Roma de la Corte Penal Internacional (CPI) (Ayala, 2002, pp. 51-52).

El Estatuto de Roma, al tipificar "Ios crímenes más graves de trascendencia para la comunidad internacional en su conjunto", que en definitiva son aquellos que protegen o pretenden proteger los derechos humanos y evitar que atrocidades "que desafían la imaginación y conmueven profundamente la conciencia humana" (Ley Aprobatoria del estatuto de Roma de la Corte Penal Internacional, 13 de diciembre de 2000), como el holocausto, los crímenes de guerra en la ex-Yugoslavia, Uganda o Afganistán, debe entenderse como un tratado en materia de derechos humanos Esta visión ampliada de los tratados de derechos humanos, sustentada sobre la idea del núcleo duro de los derechos humanos, es desarrollada por la Corte Interamericana de Derechos Humanos, en su opinión consultiva OC$26 / 20$, donde resalta que los tratados internacionales en materia de derechos humanos son tratados que tienen una naturaleza especial, porque "son un tipo específico de tratados multilaterales" (Corte Interamericana de Derechos Humanos, 2020).

Se debe destacar que no se pretende agotar en este apartado lo correspondiente a una implementación total del Estatuto de Roma, que incluya las consideraciones propias del derecho penal adjetivo, por el contrario se limita a los aspectos sustantivos, especialmente la tipificación de los crímenes atroces, siendo que el punto de interés en esta oportunidad son los crímenes de lesa humanidad, debido al contexto venezolano, y los crímenes de guerra por los conflictos armados que han existido y existen en la región Latinoamericana; entendiéndose entonces que en Venezuela el Estatuto al ser una norma de rango constitucional, pueda aplicarse directamente en los casos que los tribunales conozcan y que estén relacionados con los crímenes atroces.

Darle al Estado la posibilidad de hacer justicia utilizando el Estatuto en los términos antes expuestos, es un análisis muy limitado, que no profundiza en la falta de capacidad técnica: la carencia de conocimientos de expertos que integran el sistema de justicia nacional, la falta de recursos, o la inexistencia real de un programa efectivo de protección de testigos y víctimas. Además, en Venezuela es evidente la falta de voluntad por juzgar dichos crímenes, la cual se desprende de lo dicho por la Misión Internacional Independiente de Determinación de los Hechos sobre la República Bolivariana de Venezuela, que en sus conclusiones detalladas señalan:

(...) 486. El sistema de justicia ha tenido un papel de gran importancia y centralidad en la crisis venezolana. La Misión tiene motivos razonables para creer que, si los actores fiscales y judiciales hubieran desempeñado de manera adecuada y completa su función constitucional podrían haber evitado la comisión de muchos de estos crímenes y violaciones $\mathrm{o}$, por lo menos, podrían haber 
puesto trabas rigurosas para obstaculizar la capacidad de los miembros de los servicios de seguridad pública e inteligencia del Estado para cometerlos.

487. La Misión tiene motivos razonables para creer que, en lugar de proporcionar protección a las víctimas de violaciones de derechos humanos y delitos, el sistema de justicia ha jugado un rol destacado en la represión del Estado contra las opositoras y los opositores al Gobierno (...) (MII, 2021, p. 208)

La anterior fiscal de la CPI, Fatou Bensouda, en un informe enviado a la Sala de Cuestiones Preliminares en el marco de un procedimiento iniciado por el Estado venezolano, indicó que la situación de Venezuela I podría ser admisible por inacción ${ }^{(22)}$, destacando como fundamento jurídico el artículo 17(2)(a) y 17(2)(c) del Estatuto de Roma, donde se establece que no hay disposición a actuar en asuntos determinados, bien porque el juicio que se adelanta ha sido utilizado para "sustraer a la persona de que se trate de su responsabilidad penal", o porque el proceso no fue o no está siendo sustanciado de manera independiente o imparcial (Fatou Bensouda, 15 de junio de 2021).

En definitiva, la implementación del Estatuto de Roma en Venezuela está limitada principalmente por la falta de voluntad, y diversos aspectos relacionados con la falta de capacidad, pero la inexistencia de normas internas ajustadas al Estatuto de Roma, es un obstáculo fácilmente superable, dada la posibilidad de aplicar este conforme al artículo 23 de la Constitución, por lo que no pareciera ser una prioridad la creación de un Código especial o la modificación sustancial de normas internas para que en un futuro cercano, el sistema de justicia penal institucionalizado pueda atender los posibles casos de crímenes de lesa humanidad ocurridos en el país.

\subsubsection{Limitaciones jurisprudenciales}

Debe señalarse, brevemente, que en el caso venezolano la jurisprudencia del Tribunal Supremo de Justicia, especialmente de la Sala Constitucional, ha ido debilitando la nacionalización de las normas internacionales en materia de derechos humanos.

Ya en el año 2003, la Sala Constitucional en su Sentencia 1942, con ponencia del magistrado Jesús Eduardo Cabrera
Romero, establecía límites al artículo 23 de la Constitución venezolana, llegando incluso al atrevimiento de atribuirse para sí la función de interpretar las normas de los pactos y tratados internacionales en materia de derechos humanos, en franco desconocimiento de la Convención de Viena sobre el derecho de los tratados, del 23 de mayo de 1969, además vaciando de contenido al derecho internacional de los derechos humanos, al indicar que:

(...) A juicio de la Sala, dos elementos claves se desprenden del artículo 23: 1) Se trata de derechos humanos aplicables a las personas naturales; 2) Se refiere a normas que establezcan derechos, no a fallos o dictámenes de instituciones, resoluciones de organismos, etc., prescritos en los Tratados, sino sólo a normas creativas de derechos humanos (Sala Constitucional, 15 de julio de 2003).

Como ya se expuso previamente, los tratados en materia de derechos humanos no solo son aquellos que establecen dichos derechos, sino que también debe incluirse a los que los protegen y promueven. Esta sentencia también afectó principios esenciales como el de progresividad, pero por no ser el eje central de este trabajo no se profundizará más en ella.

Otro problema, de gran relevancia en el país es la decisión reiterada de la Sala Constitucional de declarar inejecutables las decisiones de la Corte Interamericana de Derechos Humanos. La primera vez que ello ocurrió fue en la sentencia No. 1939, del 18 de diciembre de 2008, en la que, además, indicó:

2) Con fundamento en el principio de colaboración de poderes (artículo 136 de la Constitución de la República Bolivariana

(22) "8. Significantly, having reviewed the information submitted by the domestic authorities, the potential cases that would likely arise from an investigation into the situation would be admissible in terms of inaction. This is because of the limited number of relevant domestic proceedings relating to the potential cases identified by the Prosecution; their highly limited scope relative to its findings; and the lack of concrete, progressive steps in those cases to ascertain the criminal responsibility of suspected persons. Nonetheless, given that some of the underlying conduct and specific incidents examined by the Venezuelan authorities appear to at least partially correspond to some of the underlying conduct and incidents assessed by the Prosecution as part of its potential cases, it has also conducted a genuineness assessment into potentially relevant national proceedings. This has resulted in the conclusion that the authorities are unwilling genuinely to investigate and/or prosecute such cases. This is because, according to the information available, domestic proceedings have been undertaken or national decisions made for the purpose of shielding persons from criminal responsibility, under article 17(2)(a), and/or domestic proceedings have not been conducted independently or impartially, meaning that they have been conducted in a manner which is inconsistent with an intent to bring the person concerned to justice, under article 17(2)(c) of the Statute". Para más información, véase https://www.icc-cpi.int/CourtRecords/CR2021_05505.PDF. 
de Venezuela) y de conformidad con lo dispuesto en el artículo 78 de la Convención Americana sobre Derechos Humanos, se solicita al Ejecutivo Nacional proceda a denunciar este Tratado o Convención, ante la evidente usurpación de funciones en que ha incurrido la Corte Interamericana de los Derechos Humanos, con el fallo objeto de la presente decisión (Sala Constitucional, 18 de diciembre de 2008).

La denuncia de la Convención ocurrió en el año 2012, pero evidentemente el poder judicial no se opuso a ella, pues ya la había solicitado hacía unos años, contraviniendo así el principio de progresividad y procurando dejar a los venezolanos en una situación de desprotección, que luego se vio profundizada una vez que se denunció en 2017 la Carta de la Organización de Estados Americanos.

Este escenario, expuesto de manera muy general, pretende estimular el debate y mostrar cómo el Estado Venezolano no tiene voluntad actualmente para implementar tratados en materia de derechos humanos desde una perspectiva amplia, ni de establecer la verdad de los hechos que han configurado graves violaciones de derechos humanos, proveer justicia a las víctimas, y establecer garantías de no repetición, porque el máximo tribunal del país se ha encargado de socavar las bases para ello, y en consecuencia, también se ha debilitado la implementación del Estatuto de Roma.

\subsubsection{Venezuela y los conflictos armados}

Por último, y siendo que el eje central de este análisis son los crímenes de guerra, debe destacarse que, durante el siglo $\mathrm{XX}$, no se desarrollaron guerras o conflictos armados internaciones en territorio venezolano, lo más parecido fue el bloqueo marítimo que sufrieron las costas venezolanas por las fuerzas navales inglesa, alemana e italiana entre 1902 y 1903 (Zambrano, 2013). No obstante, a nivel interno hubo un período en el que existió una guerrilla venezolana, pues en 1963 nacen las Fuerzas Armadas de Liberación Nacional (FALN), pero el proceso de pacificación se inició prontamente, en 1969, con el gobierno de
Rafael Caldera, por lo cual los movimientos guerrilleros perdieron fuerza al iniciar los años setenta (Lucha armada venezolana en los 60, octubre 2010, pp. 22-43).

Recientemente, se han vivido conflictos armados entre la Fuerza Armada Nacional y presuntos grupos disidentes de las Fuerzas Armadas Revolucionarias de Colombia (FARC-EP) que hacen vida en Venezuela. El 21 de marzo de 2021 se inició un operativo armado, que incluyó bombardeos en el estado Apure, extendiéndose más de un mes y que derivó en la movilización forzada de miles de personas hacia Colombia, militares heridos y asesinados y campesinos ejecutados extrajudicialmente, pero es difícil obtener información precisa de los hechos ${ }^{(23)}$.

En Venezuela, también hay grupos de delincuencia organizados que controlan determinadas zonas, por ejemplo, el ACNUDH hizo referencia a grupos de este tipo en la zona minera del estado Bolívar (ACNUDH, 2020), y hasta hace pocos meses una banda criminal liderada por "el Koki" dominaba de manera violenta diversas zonas de Caracas. Estas organizaciones en oportunidades se enfrentan con armas de guerra a las fuerzas de seguridad del Estado, pero por las características de la situación no puede considerarse como un conflicto armado en los términos desarrollados por el Derecho Internacional Humanitario.

Venezuela vive una Emergencia Humanitaria Compleja(24), derivada de una

(23) Para poder tener información, véase https://www.bbc.com/mundo/noticias-america-latina-56645187

(24) A finales de 1994 el Comité Permanente entre Organismos (IASC), principal órgano de políticas humanitarias de las Naciones Unidas, formuló una definición de las emergencias humanitarias complejas en la 16ava. Reunión de su Grupo de Trabajo. Véase en https:/l interagencystandingcommittee.org/system/files/legacy_files/WG16_4.pdf. Allí se dijo que el término pudo ser utilizado mucho antes; pero no fue hasta que Naciones Unidas se vio más involucrada en "emergencias humanitarias por mandatos de paz y de seguridad internacionales" que se hizo necesario adoptar una definición para ejercer su papel de movilizar asistencia humanitaria en un vínculo dinámico con el establecimiento de la paz". Véase en https://www.civilisac.org/civilis/wp-content/uploads/Manual-Derecho-a-laProtección-Internacional-en-Crisis-Mayores-20191.pdf. Se define en inglés: "a) a humanitarian crisis which occurs in a country, region, or society where there is a total or considerable breakdown of authority resulting from civil conflict and/or foreign aggression; b) a humanitarian crisis which requires an international response which goes beyond the mandate or capacity of any single agency; c) a humanitarian crisis where the IASC assesses that it requires intensive and extensive political and management coordination" (véase https://interagencystandingcommittee.org/system/files/legacy_files/WG16_4.pdf). Para tener más información sobre el tema, véase https://www.civilisac.org/emergencia-humanitaria-compleja/las-emergencias-humanitarias-complejas-caracter-politico\#: :text=Civilis\%20 DDHH)\%20A\%20diferencia\%20de,son\%20fundamentalmente $\% 20$ de $\% 20$ car $\%$ C3\%A1cter\%20pol\%C3\%ADtico.\&text=Esta $\% 20$ es\%20una $\% 20$ situaci\%C3\%B3n\%20que,entonces\%20es\%20una\%20emergencia\%20compleja. En esta fuente, se indica que: "A diferencia de las crisis humanitarias que vienen determinadas por desastres naturales o conflictos armados, las emergencias complejas son fundamentalmente de carácter político. Se trata de crisis humanitarias graves que suelen ser el resultado de una combinación de factores que van desde inestabilidad política, quiebre y fragmentación del Estado, conflictos y violencia, fracaso de políticas de desarrollo, desmoronamiento de la economía formal, desigualdades sociales y pobreza subyacente; que generan grandes impactos sobre la estabilidad cultural, civil, política y económica de las sociedades". 
crisis multifactorial, en la que se ha quebrado la institucionalidad Estatal. Ello ha derivado en graves y sistemáticas violaciones de derechos humanos, y es probablemente un factor de atención, frente a altos niveles de violencia que podrían profundizarse si no se atienden oportunamente.

\section{Conclusiones}

El análisis de los procesos de implementación de las obligaciones del Derecho Penal Internacional, particularmente de los crímenes internacionales, en estos tres países -Perú, Colombia y Venezuela- nos permite identificar algunos elementos comunes a los tres países, así como características particulares en cada uno de ellos.

Como punto de partida, hay una tarea ineludible: la plena implementación de todo el catálogo de crímenes internacionales dentro de nuestros países sigue siendo una tarea pendiente (aunque en Colombia se cuentan con más tipos implementados frente a los otros dos países). La tarea no debe comenzar desde cero: tanto en Perú como en Venezuela se cuentan con proyectos de ley sobre implementación del Estatuto de Roma que pueden servir de antecedentes importantes para la implementación en dichos países.

Frente al desafío de la ausencia de legislación expresa sobre crímenes internacionales (o de su plena implementación), los sistemas judiciales han respondido con innovaciones y alternativas interesantes. En Colombia, la falta de implementación específica encuentra una salida por el mandato de la JEP para hacer su propia calificación en torno a los crímenes internacionales, a través de un mandato constitucional expreso para hacerlo. Además, por vía de interpretación judicial, los tribunales han podido aplicar categorías del Estatuto de Roma a procesos internos. En el Perú, la aplicación del Estatuto de Roma a falta de tipos penales es más compleja, pero hemos tenido importantes decisiones que se han referido al Estatuto como medio de interpretación. Por último, en Venezuela, la interpretación del Estatuto de Roma como norma de derechos humanos que forma parte del bloque de constitucionalidad también ofrecen posibilidades de aplicación del Estatuto.

En conclusión, hay signos de innovación para utilizar o aplicar el Estatuto de Roma ante la falta de acción del legislador nacional. Empero, ello no elimina la urgencia de poder avanzar y culminar los procesos de implementación del Estatuto de Roma y otras obligaciones del Derecho Internacional de modo integral y sistemático dentro de nuestros ordenamientos, incluyendo de los principios relevantes del DIH y DPI. Ello, por las obligaciones asumidas, por el principio de complementariedad, pero, también, por los beneficios que la plena implementación ofrece.

\section{Referencias bibliográficas}

ACNUR. (2010, 28 de junio). Enmienda de Kampala al Estatuto de Roma relativa al crimen de agresión. https://www.acnur.org/fileadmin/Documentos/ BDL/2010/8015.pdf

Alto Comisionado de las Naciones Unidas para los Derechos Humanos [ACNUDH]. (2020, 15 de julio). Independencia del sistema de justicia y acceso a la justicia, incluyendo violaciones a los derechos económicos y sociales en la República Bolivariana de Venezuela, y situación de los derechos humanos en la región del Arco Minero del Orinoco. https:// cepaz.org/wp-content/uploads/2020/07/InformeBachelet-15-de-julio-2019.pdf

Asamblea de Estados Partes. (s.f). The States Parties to the Rome Statute. Assembly of States Parties to the Rome Statute. https://asp.icc-cpi.int/ en menus/asp/states $\% 20$ parties/pages/the $\% 20$ states $\% 20$ parties $\% 20$ to $\% 20$ the $\% 20$ rome $\% 20$ statute.aspx

Asamblea de Estados Partes. (2010, 25 de marzo). Resolución ICC-ASP/8/Res.9 Conferencia de Revisión. https://asp.icc-cpi.int/iccdocs/asp_docs/ Resolutions/ICC-ASP-8-Res.9-SPA.pdf

Ayala, C. (2002). La jerarquía constitucional de los tratados relativos a derechos humanos y sus consecuencias. En R. Méndez (coord.), Derecho internacional de los derechos humanos (pp. 3790). Instituto de Investigaciones Jurídicas. https:// www.civilisac.org/civilis/wp-content/uploads/ jerarquc3ada-de-los-tratados-de-ddhh-ayalacorao-1.pdf

Bensouda, F. (2021, 15 de junio). Situation in the Bolivarian Republic of Venezuela I. https://www. icc-cpi.int/CourtRecords/CR2021_05505.PDF

Centro Nacional de Historia. (2010). Lucha armada venezolana en los 60. Memorias de Venezuela, 16, 22-43. http://cnh.gob.ve/images/ PDDrmemoriasdevenezuela/Memorias16c.pdf

Comisión de Derechos Humanos [COMISEDH]. (2019). Hacia la Implementación del Estatuto de Roma de la Corte Penal Internacional (CPI) en el Perú. COMISEDH. https://comisedh. org.pe/wp-content/uploads/2016/12/Hacia-laimplementacion-del-Estatuto-de-Roma.pdf

Comisión de la Verdad y Reconciliación del Perú. (2003). Informe Final. CVR. https://www.cverdad. org.pe/ifinal/

Comisión de Justicia y Derechos Humanos del Congreso de la República del Perú. (2009, 14 de abril). Acta de la Décimo Octava Sesión Ordinaria 2008. Período Legislativo 2008-2009. 
https://www2.congreso.gob.pe/Sicr/ApoyComisiones/comision2008. nsf/1ActasComisiones/64E0FDC014AAA313052575BA0055350E/ \$FILE/ACTAJUSTICIA14-21-03-2009.pdf

Comisión Especial Revisora del Código Penal (CERCP). (2003). Adecuación de la Legislación Penal al Estatuto de Roma de la Corte Penal Internacional.

Comité Internacional de la Cruz Roja. (s.f). Treaties, State Parties, and Commentaries. https://ihl-databases.icrc.org/applic/ihl/ihl.nsf/ vwTreatiesByCountry.xsp

Comité Internacional de la Cruz Roja. (2018, 24 de setiembre). Estos son los grupos que hacen parte del conflicto armado en Colombia. https://www.icrc.org/es/document/el-nuevo-grupo-que-entra-hacerparte-del-conflicto-armado-en-colombia

Congreso de la República Bolivariana de Venezuela. (2000, 13 de diciembre). Ley Aprobatoria del Estatuto de Roma de la Corte Penal Internacional. Gaceta Oficial extraordinaria 5507.

Congreso de la República de Colombia. (2000, 24 de julio). Ley 599. Por la cual se expide el Código Penal. Diario Oficial 44097. https://www. oas.org/juridico/spanish/mesicic2_col_ley_599_2000.pdf

Congreso de la República de Colombia. (2001, 30 de julio). Acto legislativo 01 de 2001. Por medio del cual se modifican algunos artículos de la Constitución Política. Diario Oficial 44506. https://www. mineducacion.gov.co/1621/articles-90475_archivo_pdf.pdf

Congreso de la República de Colombia. (2002, 7 de junio). Ley 742. Pormedio de la cual se aprueba el Estatuto de Roma de la Corte Penal Internacional, hecho en Roma, el día diecisiete (17) de julio de mil novecientos noventa y ocho (1998). Diario Oficial 44826. https://www. funcionpublica.gov.co/eva/gestornormativo/norma_pdf.php?i=5964

Congreso de la República de Colombia. (2008, 31 de diciembre). Ley 1268. Por medio de la cual se aprueban las "reglas de procedimiento y prueba" y los "elementos de los crímenes de la Corte Penal Internacional", aprobados por la Asamblea de los Estados Parte de Corte Penal Internacional, en Nueva York, del 3 al 10 de septiembre de 2002. Diario Oficial 47219. https://www.funcionpublica.gov.co/eva/ gestornormativo/norma.php?i=34489

Congreso de la República de Colombia. (2017, 4 de abril). Acto legislativo 1 de 2017. Por medio del cual se crea un título de disposiciones transitorias de la Constitución para la terminación del conflicto armado y la construcción de una paz estable y duradera y se dictan otras disposiciones. Diario Oficial 50196. https://www.suinjuriscol.gov.co/viewDocument.asp?id=30030428

Congreso de la República de Colombia. (2019, 6 de junio). Ley 1957. Estatutaria de la Administración de Justicia en la Jurisdicción Especial para la Paz. Diario Oficial 50976. https://www.funcionpublica.gov.co/ eva/gestornormativo/norma.php?i=94590

Congreso de la República del Perú. (2005). Proyecto de Ley 14659/2005-CR.

Congreso de la República del Perú. (2007). Proyecto de Ley 1707/2007CR.

Congreso de la República del Perú. (2012). Proyecto de Ley 1615/2012CR.

Congreso de la República del Perú. (2014). Dictamen de un texto sustitutorio mediante el cual se propone la Ley del Nuevo Código Penal.
Congreso de la República del Perú. (2016). Proyecto de Ley 498/2016-CR.

Constitución Política del Perú. (1993). Presidencia de la República del Perú. https://cdn.www.gob. pe/uploads/document/file/198518/Constitucion_ Politica_del_Peru_1993.pdf

Convención contra la Tortura y Otros Tratos o Penas Crueles, Inhumanos o Degradantes. (1984, 10 de diciembre). Oficina del Alto Comisionado de las Naciones Unidas para los Derechos Humanos. https://www.ohchr.org/sp/professionalinterest/ pages/cat.aspx

Convenio de Ginebra I para aliviar la suerte que corren los heridos y los enfermos de las fuerzas armadas en campaña, 1949. (1949, 12 de agosto). Comité Internacional de la Cruz Roja. https://www. icrc.org/es/doc/resources/documents/treaty/treatygc-1-5tdkna.htm

Convenio de Ginebra II para aliviar la suerte que corren los heridos, los enfermos y los náufragos de las fuerzas armadas en el mar, 1949. (1949, 12 de agosto). Comité Internacional de la Cruz Roja. htttps://www.icrc.org/es/doc/resources/documents/ treaty/treaty-gc-2-5tdkwc.htm

Convenio de Ginebra III relativo al trato debido a los prisioneros de guerra, 1949. (1949, 12 de agosto). Comité Internacional de la Cruz Roja. https://www. icrc.org/es/doc/resources/documents/treaty/treatygc-3-5tdkwx.htm

Convenio de Ginebra IV relativo a la protección debida a las personas civiles en tiempo de guerra, 1949. (1949, 12 de agosto). Comité Internacional de la Cruz Roja. https://www.icrc.org/es/doc/ resources/documents/treaty/treaty-gc-4-5tdkyk. htm

Convención para la Prevención y la Sanción del Genocidio. (1948, 12 de setiembre). Comité Internacional de la Cruz Roja. https://www.icrc.org/ es/doc/resources/documents/misc/treaty-1948conv-genocide-5tdm6h.htm

Corte Constitucional de Colombia. (2002). Sentencia C-578/02. https://www.corteconstitucional.gov.co/ relatoria/2002/C-578-02.htm

Corte Constitucional de Colombia. (2006). Sentencia C-370/06. https://www.corteconstitucional.gov.co/ Relatoria/2006/C-370-06.htm

Corte Constitucional de Colombia. (2009). Sentencia C-488/09. https://www.corteconstitucional.gov.co/ relatoria/2009/C-488-09.htm

Corte Constitucional de Colombia. (2018). Sentencia C-080/18. https://www.corteconstitucional.gov.co/ relatoria/2018/c-080-18.htm

Corte Interamericana de Derechos Humanos. (2020, 9 de noviembre). Opinión Consultiva OC- 
26/20. https://www.corteidh.or.cr/docs/opiniones/seriea_26_esp.pdf

Corte Penal Internacional. (s.f.). National Criminal Jurisdictions. ICC Legal Tools Database. https://www.legal-tools.org/

Corte Penal Internacional. (2011, 30 de agosto). Prosecutor v. Muthaura and others. Judgment on the Appeal of the Republic of Kenya against the Decision on Pre-Trial Chamber II of 30 May 2011 entitled "Decision on the Application by the Government of Kenya Challenging the Admissibility of the Case pursuant to Article 19(2)(b) of the Statute.

Corte Penal Internacional. (2013, 31 de marzo). Prosecutor vs. Saif AlIslam Gaddafi. Decision on the admissibility of the case against Saif AlIslam Gaddafi. https://www.icc-cpi.int/Pages/record.aspx?docNo=ICC01/11-01/11-344-Red

Corte Penal Internacional. (2014, 7 de marzo). The Prosecutor v. Germain Katanga. Judgment pursuant to article 74 of the Statute. https://www.icc-cpi.int/Pages/record.aspx?docNo=ICC-01/04-01/073436-tENG

Corte Penal Internacional. (2016, 27 de setiembre). Prosecutor v. Ahmad Al Faqi Al Mahdi. Judgment and Sentence. https://www.icc-cpi. int/Pages/record.aspx?docNo=ICC-01/12-01/15-171

Corte Penal Internacional. (2019, 5 de abril). Prosecutor vs. Saif AlIslam Gaddafi. Decisión sobre la Admisibilidad. https://www.icc-cpi. int/Pages/record.aspx?docNo=ICC-01/11-01/11-662

Corte Suprema de Justicia de la República del Perú. (2009, 13 de noviembre). Acuerdo Plenario 9-2009/CJ-116. http://spij.minjus.gob. pe/Graficos/Jurisp/2010/Enero/08/AP-9-2009-CJ-116.pdf

Estatuto de Roma de la Corte Penal Internacional. (1998, 17 de julio). Naciones Unidas. https://www.un.org/spanish/law/icc/statute/spanish/ rome_statute(s).pdf

Fiscalía de la Corte Penal Internacional. (2020, 14 de diciembre). Informe sobre las actividades de examen preliminar 2020 (Colombia). https://www.icc-cpi.int/itemsDocuments/2020-PE/2020-pe-reportcol-spa.pdf.

Fiscalía de la Corte Penal Internacional. (2020, 14 de diciembre). Informe sobre las actividades de examen preliminar 2020 (Venezuela I). https://www.icc-cpi.int/itemsDocuments/2020-PE/2020-pe-reportven-i-spa.pdf.

Fiscalía de la Corte Penal Internacional. (2020, 14 de diciembre). Informe sobre las actividades de examen preliminar 2020 (Venezuela II). https://www.icc-cpi.int/itemsDocuments/2020-PE/2020-pe-reportven-ii-spa.pdf

Gurmendi, A. (2017). Conflicto armado en el Perú. La época del terrorismo bajo el derecho internacional. Fondo Editorial de la Universidad del Pacífico.

Ministerio de Justicia y Derechos Humanos del Perú. (2020). Anteproyecto de "Ley para prevenir y sancionar los crímenes internacionales y los delitos contra los derechos humanos"

Misión Internacional Independiente de Determinación de los Hechos sobre la República Bolivariana de Venezuela. (2020, 25 de setiembre). Informe de la Misión Internacional Independiente de Investigación sobre la República Bolivariana de Venezuela. https://undocs.org/es/A/ $\mathrm{HRC} / 45 / 33$

Misión Internacional Independiente de Determinación de los Hechos sobre la República Bolivariana de Venezuela. (2021, 16 de setiembre). Conclusiones detalladas de la Misión internacional independiente de determinación de los hechos sobre la República Bolivariana de Venezuela. https://www.ohchr.org/Documents/ HRBodies/HRCouncil/FFMVIA-HRC-48-CRP.5 SP.pdf

Moya, T. (2019). La figura de la atribución de la Responsabilidad establecida en el Estatuto de la Corte Penal Internacional y su compatibilidad con la Constitución de Venezuela. Editorial Jurídica Venezolana.

Parenti, P. (2010). La Inaplicabilidad de Normas de Prescripción en la jurisprudencia de la Corte Interamericana de Derechos Humanos. En G. Elsner, K. Ambos \& E. Malarino (coords.), Sistema Interamericano de Protección de los Derechos Humanos y Derecho Penal Internacional (pp. 211228). KONRAD-ADENAUER-STIFTUNG e. V. https://www.corteidh.or.cr/tablas/r26835.pdf

Plataforma Única del Estado Peruano. (2020). Ministro Fernando Castañeda se compromete a impulsar anteproyecto de ley para prevenir y sancionar crímenes internacionales. Nota de prensa. https://www.gob.pe/institucion/minjus/ noticias/84857-ministro-fernando-castaneda-secompromete-a-impulsar-anteproyecto-de-ley-paraprevenir-y-sancionar-crimenes-internacionales

Presidencia de la República del Perú. (1991, 8 de abril). Decreto Legislativo 635. Por el que se promulga el Código Penal, aprobado por la Comisión Revisora constituida por la ley núm. 25280. El Peruano. https://diariooficial.elperuano. pe/pdf/0034/codigo-penal-29.07.2020.pdf

Presidencia de la República del Perú. (2004, 29 de julio). Decreto Legislativo 957. Por el que se dicta el Código Procesal Penal. Poder Judicial. https://www.pj.gob.pe/wps/wcm/ connect/77a924804e7d8bb38ff6ff2670ef9145/ dl+957.pdf?MOD=AJPERES\&CACHEID=77a924804e7 d8bb38 ff6ff2670ef9145

Presidencia de la República del Perú. (2010, 31 de agosto). Decreto Legislativo 1094. Código de Justicia Militar Policial. Presidencia de la República. https://www.peru.gob.pe/docs/PLANES/13815/ PLAN_13815_2014_D.LEG._N\%C2\%BA_1094_ Codigo_Penal_Militar_Policial-126_pags.pdf

Protocolo I adicional a los Convenios de Ginebra de 1949 relativo a la protección de las víctimas de los conflictos armados internacionales, 1977. (1977, 8 de junio). Comité Internacional de la Cruz Roja. (https://www.icrc.org/es/document/protocolo-iadicional-convenios-ginebra-1949-proteccionvictimas-conflictos-armados-internacionales-1977

Protocolo II adicional a los Convenios de Ginebra de 1949 relativo a la protección de las víctimas de los conflictos armados no internacionales, 1977. 
(1977, 8 de junio). Comité Internacional de la Cruz Roja. https://www.icrc.org/es/doc/resources/ documents/misc/protocolo-ii.htm

Protocolo Facultativo de la Convención sobre los Derechos del Niño relativo a la participación de los niños en conflictos armados. (2000, 25 de mayo). Oficina del Alto Comisionado de las Naciones Unidas para los Derechos Humanos. https:// www.ohchr.org/sp/Professionallnterest/Pages/ OPACCRC.aspx

Reyes, M. (2021). Una tarea pendiente: apoyar la plena implementación del Estatuto de Roma. Instituto de Democracia y Derechos Humanos de la Pontificia Universidad Católica del Perú. https:// idehpucp.pucp.edu.pe/notas-informativas/unatarea-pendiente-apoyar-la-plena-implementaciondel-estatuto-de-roma/

Sala Constitucional del Tribunal Supremo de Justicia de Venezuela. (2003, 15 de julio). Sentencia 1942. http://historico.tsj.gob.ve/decisiones/scon/ julio/1942-150703-01-0415.HTM

Sala Constitucional del Tribunal Supremo de Justicia de Venezuela. (2008, 18 de diciembre).
Sentencia 1939. http://historico.tsj.gob.ve/decisiones/scon/ diciembre/1939-181208-2008-08-1572.HTML

Sala Penal Especial de la Corte Suprema de Justicia de la República del Perú. (2009, 7 de abril). Sentencia contra el expresidente Alberto Fujimori. Expediente N ${ }^{\circ}$ AV 19-2001 (acumulado). Casos Barrios Altos, La Cantuta y sótanos SIE. https://derechoshumanos.pe/2009/04/ sentencia-de-la-corte-suprema-contra-fujimori/

Salmón, E. (2007). El Derecho Internacional Humanitario y su relación con el Derecho interno de los Estados. Palestra Editores.

Tribunal Constitucional del Perú. (2015, 8 de julio). Sentencia recaída sobre el Expediente 022-2011-PI/TC. Demanda de inconstitucionalidad interpuesta contra el articulo único de la Ley 29548, diversos artículos del Decreto Legislativo 1094 y diversos artículos del Decreto Legislativo 1095. https://www.tc.gob.pe/jurisprudencia/2015/00022-2011-Al.pdf

Tribunal Penal Internacional para la Ex Yugoslavia. (1995, 2 de octubre). Prosecutor v. Dusko Tadic a/k/a "Dule". Decision on the Defence Motion for Interlocutory Appeal on Jurisdiction. https://www.icty.org/x/cases/ tadic/acdec/en/51002.htm

Zambrano, M. (2013). El bloqueo Naval a Venezuela (1902/1903) como elemento cristalizador de un nuevo principio de derecho internacional. http://sedici.unlp.edu.ar/bitstream/handle/10915/32378/Documento_ completo_.pdf?sequence $=4$ (बifl 